\title{
Estructura espacial de los flujos de Inversión Exterior Directa en España. Primeros pasos para la elaboración de una cartografía financiera*
}

\author{
Juan Carlos Fernández CELA \\ Departamento de Ciencia Política y de la Administración III \\ Facultad de Ciencias Políticas y Sociología \\ Universidad Complutense de Madrid \\ juancarlosfernandezcela@yahoo.es
}

Recibido: 27-01-2015

Aceptado: 30-06-2015

\section{RESUMEN}

Los flujos financieros internacionales no circulan de forma aleatoria entre los distintos países, sino que lo hacen a través de una compleja cartografía de relaciones espaciales, donde los centros financieros tienen un papel relevante. Esta movilidad genera un impacto importante en los territorios por donde atraviesa, que desborda el plano económico y condiciona las relaciones políticas entre los distintos Estados que intervienen. Este artículo pretende identificar algunos rasgos de la estructura espacial de los flujos financieros internacionales que llegan a España en forma de Inversión Exterior Directa (IED).

Palabras clave: geografía financiera; flujos financieros internacionales; cartografía del capital; Inversión Exterior Directa; centros financieros.

\section{The Spatial Structure of Foreign Direct Investment Flows to Spain. First Steps in the Elaboration of a Financial Cartography}

\begin{abstract}
International financial flows do not circulate randomly between countries. Instead, they do so through a complex mapping of spatial relationships, where financial institutions play an important role. This mobility generates a significant impact on the regions where it crosses through, which goes beyond the economic sphere and determines the political relations between the various states involved. This article aims to identify some features of the spatial structure of international financial flows to Spain in the form of Foreign Direct Investment (FDI).
\end{abstract}

\footnotetext{
* Me gustaría agradecer el esfuerzo y dedicación que han tenido en este trabajo los evaluadores y el resto del personal que colabora en esta revista. Sin duda, sus aportaciones han contribuido a mejorarlo y ha permitido que se haya podido abordar desde una perspectiva más rigurosa y sistemática.
} 
Key words: financial geography; international financial flows; mapping capital; Foreign Direct Investment; financial centers.

\section{Estrutura espacial dos fluxos de investimento direto estrangeiro na Espanha. Primeiros passos para a elaboração de uma cartografia financeira}

\section{RESUMO}

Os fluxos financeiros internacionais não circulam aleatoriamente entre países diferentes, mas eles fazem isso através de um mapeamento complexo de relações espaciais, onde os centros financeiros têm um papel importante. Essa mobilidade gera um impacto importante nos territórios onde ele passa que ultrapassa em termos econômicos e condições as relações políticas entre os vários Estados envolvidos. Este artigo visa identificar algumas características da estrutura espacial dos fluxos financeiros internacionais, chegando a Espanha sob a forma de investimento estrangeiro direto (IED).

Palavras-chave: Geografia financeira; fluxos financeiros internacionais; cartografia do capital; investimento direto estrangeiro; centros financeiros.

\section{REFERENCIA NORMALIZADA}

Fernández Cela, Juan Carlos (2015) "Estructura espacial de los flujos de Inversión Exterior Directa en España. Primeros pasos para la elaboración de una cartografía financiera". Geopolítica(s). Revista de estudios sobre espacio y poder, vol. 6, núm. 1, 107-136.

SUMARIO: Introducción. 1. Estado de la cuestión. 2. Configuración espacial de las cadenas financieras de inversión: estructura de los territorios por donde circula el capital. 3. Estructura espacial de las cadenas financieras de inversión: países de origen y sectores de inversión. Conclusiones. Bibliografía.

\section{Introducción}

¿Por qué una empresa estadounidense realiza una adquisición en España a través de una sociedad neerlandesa en vez de hacerlo directamente? ¿Cómo es posible que algunos de los mayores inversores extranjeros en España sean sociedades españolas? ¿Por qué Luxemburgo, un pequeño Estado que apenas cuenta con 550.000 habitantes, es el tercer mayor inversor en España? No son cuestiones que tengan una única y sencilla respuesta. Los flujos financieros que suministran capital a España dibujan sobre el territorio una ruta de paso muy determinada. Esta geografía del capital tiene una lógica compleja y su impacto cuantitativo y cualitativo en la economía es determinante para su evolución. La identificación de los espacios por donde circula, su cuantificación y periodicidad, así como la consolidación en el tiempo, son aspectos importantes que trasvasan la esfera de relaciones económicas para entrar de lleno en el plano geopolítico.

No es sencillo seguir los pasos del capital. La reconstrucción del itinerario que trazan los circuitos financieros internacionales es complejo por múltiples razones, y tal vez una importante es que la estructura de las redes financieras maneja productos 
sofisticados y volátiles, donde es difícil establecer el entramado societario que mueve el capital, así como los lugares de origen, tránsito y destino del mismo.

La hipótesis de este trabajo está ligada a la existencia de una relación bidireccional entre los movimientos financieros internacionales y la estructura espacial de los países de tránsito. La circulación del capital condiciona su territorio de paso; al mismo tiempo, las diferencias entre espacios inciden en su intensidad, dirección e impacto. La interacción del capital sobre el territorio tiene una estructura reticular y una dimensión global. Esta red tiene un carácter nodal, compuesta por diferentes puntos que juegan un papel complementario en el sistema y en el territorio por donde circula el capital. La construcción de una geografía financiera pasa necesariamente por el análisis de los procesos que la conforman, y que en ocasiones están ligados a esta lógica espacial de los movimientos de capital. Se contempla así, desde esta perspectiva, como un intento de establecer las diferencias espaciales que genera la movilidad del capital, así como su impacto diferencial en el territorio. Los flujos de inversiones tienen una influencia directa en los espacios por donde circulan, ya que existen fuerzas centrípetas que permiten a determinados territorios acumular capital o convertirse en puntos de paso del mismo (investment hub), con las consiguientes ventajas y posibilidades de desarrollo. Junto a ellas, existen también fuerzas centrífugas que permiten dispersar el capital acumulado hacia terceros espacios (spillover). Su circulación tiene una estructura territorial compleja pero no aleatoria, existiendo flujos regulares entre diversos países que configuran una cartografía financiera de escala global consolidada en el tiempo.

Es evidente que la elaboración de un mapa de estas características es complejo, y supera con mucho las pretensiones de este trabajo. El objetivo que se plantea aquí es mucho más sencillo, y viene determinado por la existencia de una información cuantitativa limitada que supone un obstáculo importante para poder avanzar en este tema. Se establece en primer lugar el estado de la cuestión, analizando algunos trabajos recientes realizados a consecuencia de un creciente interés por la geografía financiera, y estableciendo algunas tendencias comunes entre expertos. En efecto, los mecanismos espaciales de contagio y propagación de la crisis económica han despertado su curiosidad, y ponen de manifiesto la importancia que las diferencias espaciales juegan en este proceso. El segundo objetivo se centra en realizar un boceto sobre cómo sería una cartografía de la inversión extranjera directa en España. La idea principal es determinar quiénes son los principales inversores no residentes en España, e identificar la ruta que recorre el capital para llegar a su destino.

El análisis de la información cuantitativa utilizada está basado en la explotación estadística de DataInvex, un banco de datos dependiente de la Secretaría de Estado y Comercio que recoge las principales magnitudes de Inversión Exterior Directa en España (IED) desde 1993 hasta la actualidad. Se puede hablar de IED cuando un inversor adquiere o aumenta su participación en una sociedad que opera fuera del territorio donde reside. El principal indicador utilizado en este trabajo es el denominado stock de posición inversora, que mide el valor total de los activos que los 
inversores directos mantienen en empresas de un país diferente al suyo. Este indicador permite identificar el país de origen, los puntos de tránsito y el destino final de una determinada inversión y establecer el valor total de la misma. Es muy útil para el análisis geográfico en la medida en que permite establecer no sólo la matriz origen-destino del capital, sino su itinerario espacial y el impacto cuantitativo que genera en los distintos sectores de actividad de la economía española (ICE, 2013).

Un inversor extranjero puede, por tanto, realizar una inversión directa en España, o bien por medio de una sociedad localizada en un tercer país. Se habla de "países de tránsito" cuando existen centros espaciales que concentran sistemáticamente la inversión desde los Estados de origen a los de destino. La información analizada permite reconstruir el itinerario espacial que recorre el capital invertido, identificando los denominados "países últimos" o lugares de procedencia del capital, y los "países de tránsito" o zonas de paso del mismo hasta que el capital llega a España ${ }^{1}$.

Con objeto de presentar con mayor claridad los resultados, se ha optado por organizar el análisis desde una triple perspectiva que coincide con las secciones en que se divide este trabajo. Hasta el momento no existe en España un excesivo interés en el análisis de esta temática, por lo que es importante plantear una sección completa sobre el estado de la cuestión. En ella se recogen algunas de las principales investigaciones que existen sobre los movimientos internacionales de capital, y su impacto en el territorio. Resulta significativo el creciente interés que este tema despierta por parte de destacados analistas y algunos de los mayores organismos internacionales, que están desarrollando en la actualidad líneas de investigación en esta materia.

El segundo paso consiste en analizar el caso español, desarrollado en la tercera parte. En ella se analiza la estructura espacial de los flujos financieros que llegan al país, estableciendo la dimensión del fenómeno, los principales puntos por donde circula el capital y su impacto desigual. Finalmente, la cuarta sección se centra en analizar el lugar de procedencia de la inversión exterior. Se intenta determinar los países de origen, analizar su impacto en la estructura económica y establecer cuáles son las principales sociedades que invierten en los sectores estratégicos.

\section{Estado de la cuestión}

El interés por la crisis financiera ha puesto en primer plano el análisis espacial de los flujos de capital entre países. En España, la geografía no ha prestado hasta el

\footnotetext{
${ }^{1}$ Corresponde a la información registrada por la Subdirección General de Comercio Internacional de Servicios e Inversiones en el modelo D-1A correspondientes a la declaración de inversión extranjera en sociedades no cotizadas, sucursales y otras formas de inversión.
} 
momento excesiva atención a este aspecto. No ocurre lo mismo en otros países, donde la geografía (Seo, 2011; Agnew, 2012) y especialmente la economía (MilesiFerreti y Tille, 2011; Palmberg, 2012) están investigando los mecanismos de propagación de la crisis por el territorio. Hay una cierta coincidencia en determinar que la cercanía espacial es un factor relevante en el proceso de contagio de la crisis. Los países limítrofes tienen más posibilidades de ver alterado su sistema financiero debido a la adquisición de activos "tóxicos" procedentes de países donde se gestaron (Hobza y Zeugner, 2014).

Existe también un cierto consenso en determinar que no todos los espacios han jugado el mismo papel en este proceso, y tampoco han sufrido el mismo impacto. Baldacci, Dell'Erba y Poghosyan (2011) han analizado los canales de transmisión espacial en el mercado de bonos soberanos de veinticuatro economías emergentes entre 1995 y 2010. Para ellos en la propagación intervienen, además de la proximidad geográfica, lazos comerciales y financieros entre las economías emergentes y los países centrales, que interactúan de forma sincronizada.

Un referente de este tipo de análisis es el estudio de Milesi-Ferreti y Tille (2011) sobre el impacto de la crisis en el comportamiento espacial de los flujos de capital, colapsando su circulación entre países como consecuencia de la desconfianza que han generado algunas economías europeas como la española. Aquellos espacios que tienen un mayor nivel de dependencia de los mercados financieros internacionales han sufrido un mayor impacto de los mismos. Los países emergentes están resistiendo en mejores condiciones a este fenómeno, por el contrario los países desarrollados están en niveles muy por debajo de los existentes antes de la crisis (Greene y Kuswa, 2012).

Una de las respuestas que han adoptado los mercados financieros como mecanismos de respuesta a la crisis es la diversificación de la cartera de inversión en activos de sociedades localizadas en distintos países. Un hecho eminentemente financiero tiene importantes implicaciones de carácter espacial, ya que permite un aumento en la demanda de activos de los mercados emergentes y una mayor integración entre mercados y espacios.

Sin embargo, hay estudios donde se matiza la importancia del factor espacial en las relaciones de mercados financieros. Asgharian, Hess y Liu (2013) han desarrollado un modelo econométrico aplicado a las transacciones realizadas entre cuarenta y un países durante dieciséis años. Para su análisis se considera el peso de seis variables diferentes: dos factores de carácter financiero (volatilidad del tipo de cambio y diferencias en la evolución anual de la inflación); tres de carácter económico (nivel de comercio bilateral, inversión extranjera directa bilateral, y similitud en la estructura industrial); y la cercanía territorial. Concluyen que "los factores de carácter económico afectan a la dependencia entre los mercados de capital en mayor medida que la proximidad geográfica o la integración financiera" (Asgharian, Hess y Liu, 2013: 4751). En este caso la localización no sería para estos autores un factor 
de primer nivel a la hora de explicar los mecanismos que regulan las relaciones entre distintos mercados de capital.

La crisis económica ha modificado la topología de los flujos financieros internacionales, que tienen un proceso de difusión espacial en forma de red a través de un modelo centro-periferia de alcance global. Los países de tránsito constituyen en este contexto los espacios centrales de la red. Funcionan como centros neurálgicos de concentración de capital que recibe, absorbe, canaliza y discrimina su posterior difusión al resto del territorio. Sander, Kleimeier y Heuchemer $(2013$; 2014) han analizado el comportamiento de los movimientos de capital anteriores y posteriores a la crisis financiera. Al amparo de la misma se ha producido un cierto resurgimiento de las fronteras culturales en los movimientos de capital, que contrasta con la etapa anterior caracterizada por una mayor difusión, integración y sincronización de los mercados internacionales. El "repliegue" de las inversiones a sus espacios culturales de origen, se produce en un contexto de recesión generalizada como estrategia de respuesta ante la crisis. Se trataría en este caso de incrementar el nivel de seguridad y garantías de la inversión ante posibles situaciones de quiebra o default.

Otro de los principales efectos ha sido una reducción generalizada en el volumen de valores que circula entre países, y una desigual respuesta de la red de centros por donde circula el capital. Aquellos puntos mejor conectados en el espacio financiero absorben mejor los problemas derivados de la crisis, en la medida en que permiten disipar hacia los espacios periféricos los efectos adversos de la misma (Chinazzi et al., 2012).

Este fenómeno de deslocalización del riesgo financiero ha favorecido la propagación de la crisis en el territorio desde los espacios centrales a los periféricos o semiperiféricos, desplazando espacialmente el problema y concentrándolo en aquellos puntos más vulnerables del sistema. La posición periférica de algunos espacios financieros receptores, dificulta sus posibilidades de desplazarlos de nuevo a terceros espacios, multiplicando en ellos de forma exponencial los efectos negativos de la crisis, ya que vienen agravados por los que se originan desde los espacios centrales. Incluso se sostiene que la existencia de una creciente interdependencia entre los distintos puntos financieros, localizados en diferentes espacios, "han creado un ambiente de retroalimentación para generar respuestas amplificadas a shocks en el sistema financiero" (Gai y Kapadia, 2010: 5). La lógica espacial del sistema favorece la multiplicación de los efectos negativos, incrementado el nivel de riesgo global y haciendo más compleja la toma de decisiones para hacer frente a la crisis.

Hondroyiannis, Kelejian y Tavlas (2009) y Kelejian, Tavlas y Hondroyiannis (2006) han centrado el análisis en el impacto de la transmisión espacial del riesgo financiero en el mercado de divisas de los países emergentes. Sugieren la existencia de un impacto desigual en función de dos factores importantes: el nivel de comercio existente entre países y la distancia espacial entre los mismos. El resultado de todo 
ello es la aparición de una cartografía de flujos financieros que tiene, en este contexto, un impacto sustancial así como global.

Palmberg (2012) plantea que las relaciones financieras existentes entre distintos espacios se establecen a través de fuerzas centrífugas que expulsan capital hacia otros territorios y centrípetas que lo absorben en determinados espacios. Los flujos centrífugos de capital entre centros financieros se encuentran ligados entre otros a la existencia de distintos usos horarios, regulaciones específicas de distintos Estados o una estructura institucional diferenciada. Por el contrario, las fuerzas centrípetas permiten a los espacios financieros centrales desarrollar en torno a ellos una economía de aglomeración que recuerda a la que hace cuatro décadas se generaron en los espacios industriales.

La generación de economías de escala en determinados centros financieros permite algunas ventajas de competitividad entre regiones. El impacto de este fenómeno para determinados espacios centrales ha sido sin duda positivo para hacer frente a la crisis financiera, al permitir a través de estos mecanismos desplazar algunos efectos negativos de la crisis a otros territorios. Esto ni mucho menos significa que el origen de la misma sea un simple mecanismo de transferencia de unos puntos a otro, "liberando" de responsabilidad política a los países más afectados por la crisis. Sin embargo, sí parece existir una cierta coincidencia en señalar que la creciente interdependencia del sistema financiero internacional ha facilitado la propagación de determinados efectos perniciosos de la crisis desde espacios financieros centrales a periféricos (Feroldi y Gaffeo, 2013).

¿Qué elementos espaciales componen la red financiera internacional? Nagurney y Cruz $(2001 ; 2003$, Gráfico 1) identifican tres niveles diferentes: agentes de origen, intermediarios y consumidores. A pesar de contar con una diferente denominación, Seo (2011) coincide también en identificar una triple dimensión en los puntos espaciales claves de la red financiera internacional: puntos de origen del capital, espacios de tránsito y lugares de destino de las inversiones.

La circulación del capital desde su punto de origen hacia su destino final puede ser directo, o establecer lugares de tránsito. Estos espacios comparten unos rasgos específicos que podrían explicar, al menos parcialmente, la cartografía de relaciones financieras.

El rasgo más característico tal vez sea el carácter inmaterial de los flujos financieros. No es lo mismo analizar la movilidad de elementos mensurables como puede ser el tráfico de mercancías o de población, que los movimientos de capital que se realizan a partir de plataformas informáticas donde es difícil obtener información. Las inversiones transfronterizas están compuestas en algunos casos por productos de gran complejidad, elaborados en ocasiones por matemáticos y físicos de primer nivel a través de desarrollos informáticos altamente especializados (Weatherall, 2013). La repercusión geográfica se liga al surgimiento de una compleja cartografía del capital, basada en interrelaciones entre distintos puntos que desempeñan un papel especializado en la red financiera internacional. 
Gráfico 1. Estructura espacial de la red financiera internacional. Países de origen, lugares de paso y puntos de destino de la inversión extranjera de capital

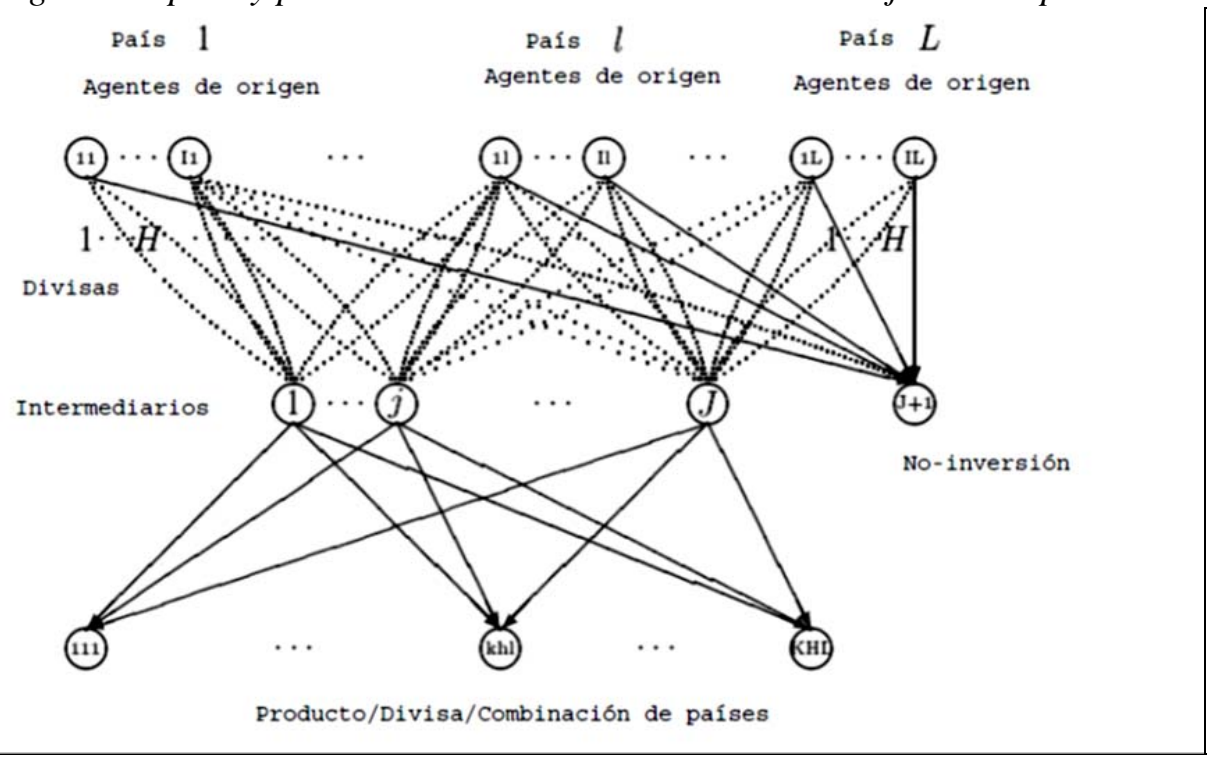

Fuente: Nagurney y Cruz (2003).

La crisis financiera ha puesto de manifiesto cómo la volatilidad de estas inversiones especulativas en un determinado espacio afecta directamente a la estructura productiva de su economía "real". La transmisión espacial del riesgo estaría ligada a la movilidad de numerosos productos financieros altamente sofisticados que aprovechan las asimetrías de precios e información que existen en diferentes centros financieros (Warde, 2012). Esta complejidad desplaza el debate desde el terreno político al técnico, justificando a partir de estos argumentos el destino "inevitable" que tienen las duras medidas contra la crisis que afectan a la población (Agnew, 2012). En la misma línea crítica se encuentra el trabajo de Harvey (2012), que señala la importancia de los flujos financieros internacionales como elemento cardinal en la hegemonía del capital.

Un segundo elemento importante es la velocidad de desplazamiento del capital. Es bien conocido que las plataformas financieras permiten movilizar una ingente cantidad recursos en poco tiempo de un punto a otro de la red. Este desarraigo del capital genera efectos en muchos casos perniciosos sobre los espacios de circulación, especialmente aquellos afectados por fenómenos de spillover que, como es el caso español, tienen una creciente dependencia de la inversión procedente de los espacios centrales (Baldacci, Dell'Erba y Poghosyan, 2011). Si los mercados son sensibles a los cambios económicos, los espacios que lo soportan se ven afectados por ello. Gómez Lende (2014) expresa de forma muy gráfica este proceso para el 
caso argentino, cuando habla de "movimientos de diástole y sístole" en referencia a los desplazamientos de capital de un punto a otro del territorio.

Desde el punto de vista geográfico, un rasgo importante está vinculado al impacto diferencial que la geografía del capital ejerce en el territorio. No todos los espacios absorben por igual los flujos financieros que circulan sobre ella (Stiglitz, 2010). $\mathrm{Su}$ incidencia es diferente porque la estructura espacial receptora varía sensiblemente de unos países a otros, incluso dentro del mismo país ${ }^{2}$. A medida que aumenta la centralidad del núcleo financiero el impacto tiene efectos más positivos para el país donde se localiza. Olivié, Pérez y Macías $(2010 ; 2011)$ establecen una triple dimensión para evaluar el impacto que la inversión exterior tiene en un determinado espacio: factores, mecanismos y procesos. El problema que plantean es que el proceso de ósmosis entre los flujos de capital y su impacto en el territorio es complejo. Los factores que intervienen pueden tener un efecto positivo para una parte de la economía regional, pero al mismo tiempo negativo para otra.

La primera condición para su desarrollo es la existencia de procesos de acumulación inicial de capital en espacios de origen. Existen determinados territorios que, debido a varias causas, son capaces de crear excedentes de capital que se dirigen hacia otras zonas. La existencia de diferencias territoriales en las condiciones de generación de plusvalor facilita la movilidad del capital, desplazándose desde aquellos puntos donde la obtención de beneficio es menor o cuenta con menos garantías, hacia otros espacios donde sea posible obtener mayores rentas.

Hale señala cómo la importancia de las asimetrías de información en los mercados de capitales es comúnmente aceptada como una de las principales razones de sesgo de la inversión (2012; 2014). Gai y Kapadia (2010) establecen cómo la llegada de productos financieros complejos, como los swaps, instrumentos de deuda, fondos soberanos o productos de crédito son la forma que adopta el capital para desplazarse de un lugar a otro en búsqueda de beneficios, formando una compleja red de instrumentos y relaciones.

El segundo componente de la red son los espacios receptores de capital, capaces de conjugar una elevada rentabilidad y una determinada seguridad jurídica de la inversión ligada a su capacidad de pago. La evolución del diferencial de riesgo país ha puesto de manifiesto cómo los flujos de capital exterior se ralentizan o disminuyen cuando se pone en cuestión algunos de estos dos elementos, desviándose el capital hacia espacios más seguros.

La posición de los territorios ante la morfología de los flujos de capital viene determinada por la existencia de una acumulación de inversiones en algunos territorios, que contrasta con el desabastecimiento de otros. La posibilidad de captar o ser

\footnotetext{
${ }^{2}$ El impacto de los flujos de capital invertidos en Hong Kong es muy diferente del que ejerce sobre otros centros financieros de China.
} 
un espacio de tránsito de capital modifica la estructura económica y laboral de los territorios receptores. En el caso de la IED, es evidente que un incremento de la misma supone que uno o varios sectores de actividad tienen una clara dependencia de capital extranjero. Por el contrario, aquellos territorios donde el impacto de la IED es menor, cuentan con un menor grado de interconexión a los mercados internaciones, un elemento que tiene ventajas e inconvenientes.

\section{Configuración espacial de las cadenas financieras de inversión: estructura de los territorios por donde circula el capital}

Se considera país inmediato o de tránsito como el conjunto de Estados donde se emiten las órdenes directas de inversión ${ }^{3}$. Al igual que ocurre con la distribución espacial en otros aspectos importantes de la economía española, como es el caso de los flujos de deuda soberana, la movilidad de las inversiones extranjeras en España está concentrada en un reducido número de países (Fernández, 2014).

La información, procedente de la Dirección General de Comercio e Inversiones (2014), señala que en 2012 se han registrado en España inversiones en tránsito emitidas desde 91 Estados diferentes por valor de 361.550 millones de euros, un $80,58 \%$ de las cuales procede de la UE. El valor, medido según el stock de posición inversora, señala que el 78,82\% se concentra en apenas 7 Estados, Países Bajos, Italia, Luxemburgo, Francia, EE UU, Alemania y Reino Unido (Tabla 1$)^{4}$.

Una cuarta parte del valor total de la inversión extranjera en España procede de Países Bajos, seguido por Italia y Luxemburgo, que alcanzan valores por encima del $10 \%$. El resto de los grandes inversores se sitúan en un umbral que oscila entre el $8,96 \%$ de Francia y el 6,68\% de Reino Unido. La concentración es aún más evidente cuando se observa que el resto de inversores está compuesto por 84 Estados, que tienen una participación poco relevante como inversor en España. Algunos de ellos son potencias económicas de primer nivel, como es el caso de Japón, Canadá, Corea del Sur, Brasil, India o China entre otras. Sin embargo entre todas ellas apenas representan una inversión de 76.587 millones de euros $(21,18 \%)$, inferior en su conjunto incluso al valor de la existente en Países Bajos, que es de 90.684 millones $(25,08 \%)$.

\footnotetext{
${ }^{3}$ Por el contrario, se entiende por país último como el lugar de residencia del inversor, aunque sus fondos se canalicen a través de un país inmediato.

${ }^{4}$ Considerado como la valoración de una inversión directa acumulada en un momento determinado. Corresponde por tanto a la cuantía global que tiene en España los inversores, públicos o privados, residentes en un determinado país. Mide el valor global de todo el conjunto de inversiones realizadas desde un determinado país en una fecha concreta, con independencia del momento en que estas se realizaron.
} 
Tabla 1. Principales inversores en España

(según stock de posición inversora valorada en 2012, en miles de euros)

\begin{tabular}{|l|r|r|l|c|r|}
\hline País inmediato & \multicolumn{1}{c|}{ Stock } & \multicolumn{1}{c|}{$\%$} & País último & \multicolumn{1}{c|}{ Stock } & \multicolumn{1}{c|}{$\%$} \\
\hline Países Bajos & $90.684 .749,02$ & 25,08 & EE UU & $57.308 .484,24$ & 15,85 \\
\hline Italia & $45.803 .783,38$ & 12,67 & Italia & $48.605 .765,35$ & 13,44 \\
\hline Luxemburgo & $39.467 .174,21$ & 10,92 & Francia & $37.124 .280,43$ & 10,27 \\
\hline Francia & $32.391 .051,24$ & 8,96 & Reino Unido & $35.455 .403,18$ & 9,81 \\
\hline EE UU & $26.932 .821,32$ & 7,45 & Alemania & $28.973 .034,70$ & 8,01 \\
\hline Alemania & $25.535 .687,47$ & 7,06 & México & $19.465 .129,18$ & 5,38 \\
\hline Reino Unido & $24.147 .273,32$ & 6,68 & Luxemburgo & $19.241 .314,99$ & 5,32 \\
\hline Subtotal & $284.962 .539,96$ & 78,82 & Subtotal & $246.173 .412,07$ & 68,09 \\
\hline Resto inversores & $76.587 .518,38$ & 21,18 & & $115.376 .646,27$ & 31,91 \\
\hline Total & $\mathbf{3 6 1 . 5 5 0 . 0 5 8 , 3 4}$ & $\mathbf{1 0 0 , 0 0}$ & Total & $\mathbf{3 6 1 . 5 5 0 . 0 5 8 , 3 4}$ & $\mathbf{1 0 0 , 0 0}$ \\
\hline
\end{tabular}

Fuente: DataInvex al 4/08/2014 y elaboración propia.

El nivel de internacionalización de la inversión extranjera es, desde esta perspectiva, poco diversificada en la medida en que procede de un reducido número de Estados, la mayor parte de ellos miembros de la UE. Tal vez sea necesario potenciar las relaciones políticas y económicas con otros espacios con el objeto de intensificar los flujos financieros con países emergentes (Brasil, Rusia) o regiones geopolíticas que, como el Sudeste Asiático, tienen una presencia poco significativa en España.

La ruta de inversión en España no tiene un carácter lineal ligado a flujos simples de origen-destino, donde está identificado con claridad las empresas que invierten y su procedencia. Este proceso tiene una estructura compleja que genera, entre otros aspectos, un flujo internacional permanente de circulación del capital. Para comprender en su totalidad este sistema de funcionamiento sería necesario un estudio que excede las dimensiones de este trabajo. No obstante, el análisis de la información sí permite establecer algunos aspectos que juegan un papel destacado; el esquema de circulación de capital que se invierte en España tiene un carácter circular y afecta, en su forma más compleja, a múltiples países (Gráfico 2). El papel que desempeñan los países en tránsito en este proceso es de investment hub, un punto donde converge una parte sustancial de la circulación de capital antes de dirigirse directamente al lugar de destino, en este caso España. Son por tanto esenciales a la hora de entender la lógica de localización y movilidad espacial del capital.

A pesar de las dudas sobre la solvencia que durante varios años ha tenido el sistema financiero español, el saldo final ha crecido en los últimos años. El valor de la inversión se ha incrementado un 19,4\% entre 2007 y 2012. El análisis de la serie temporal revela que la mayor parte del mismo se produjo entre 2007 y 2009 . No obstante, entre 2010 y 2012 el período de mayor incertidumbre de la economía española, se produjo un proceso de contracción de la IED disminuyendo su valor de manera sensible, aunque el saldo general se mantiene positivo. 
Gráfico 2. Flujo de capital de la IED en España: esquema organizativo

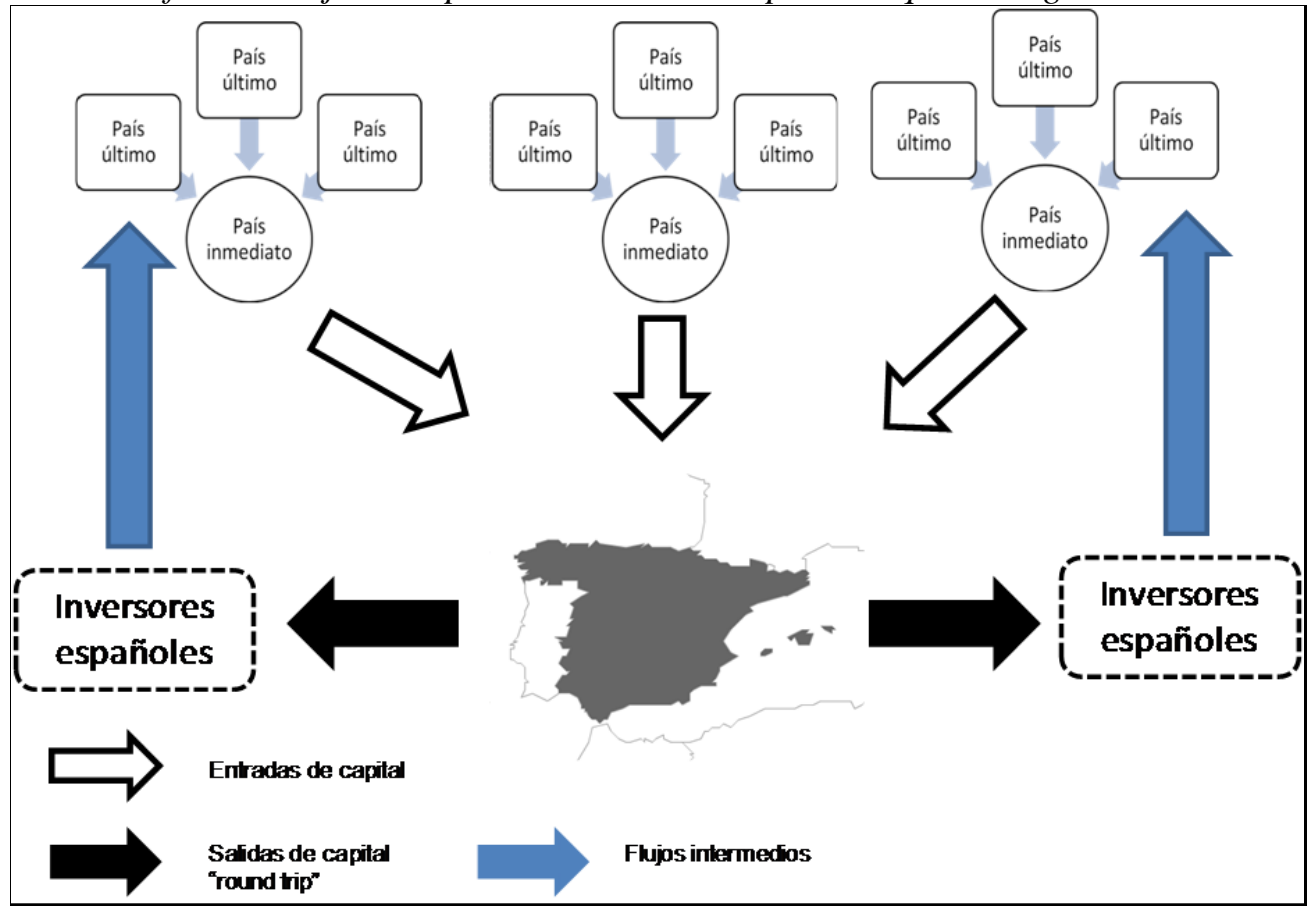

Fuente: DataInvex y elaboración propia.

Por zonas geográficas el valor de la inversión ha crecido en todas las regiones, con excepción de América del Norte, que ha disminuido un 40,95\% en cinco años. Resulta significativo el incremento del valor de la inversión procedente de paraísos fiscales, un 489,69\% entre 2007 y 2012, que pone de relieve la creciente importancia de estos espacios en el flujo financiero de entrada de capital (Tabla 2). Estos resultados, con oscilaciones muy sustanciales en períodos muy cortos, pone de manifiesto la volatilidad de los mercados financieros y el continuo cambio de valor de las inversiones (UNCTAD, 2014). En ocasiones esto responde a movimientos reales de inversión de una empresa extranjera que abre o incrementa su actividad en España. Sin embargo, una parte importante del stock acumulado corresponde a las Empresas de Tenencia de Valores Extranjeros (ETVE), un tipo de sociedad mercantil con participación extranjera que goza de numerosos beneficios fiscales, similares incluso a los que existen en los paraísos fiscales. Normalmente se encuentran asociadas a actividades con un elevado contenido especulativo no ligado a la denominada "economía real" (Villaverde y Maza 2012). 
Tabla 2. Valor del stock acumulado en España según posición inversora (en miles de euros)

\begin{tabular}{|l|r|r|r|}
\hline \multicolumn{1}{|c|}{ Región inmediata } & \multicolumn{1}{c|}{2007} & \multicolumn{1}{c|}{2012} & $\begin{array}{c}\text { Dif. 2007-2012 } \\
\text { (en \%) }\end{array}$ \\
\hline O.C.D.E. & $294.461 .088,45$ & $335.075 .905,57$ & 13,79 \\
\hline EUROPA & $242.046 .827,83$ & $302.803 .789,82$ & 25,10 \\
\hline UE27 & $230.638 .026,20$ & $291.367 .737,71$ & 26,33 \\
\hline LATINOAMÉRICA & $7.118 .532,00$ & $18.433 .362,12$ & 158,95 \\
\hline AMÉRICA DEL NORTE & $50.696 .303,35$ & $28.921 .428,67$ & $-42,95$ \\
\hline RESTO DE AMÉRICA & $102.842,86$ & $1.596 .480,14$ & $1.452,35$ \\
\hline ASIA Y OCEANÍA & $2.450 .139,55$ & $9.145 .080,96$ & 273,25 \\
\hline ÁFRICA & $328.231,04$ & $649.916,63$ & 98,01 \\
\hline PARAISOS FISCALES & $1.514 .124,23$ & $8.928 .611,75$ & 489,69 \\
\hline
\end{tabular}

Fuente: DataInvex al 4/08/2014 y elaboración propia.

Desde el punto de vista geográfico, hay dos rasgos relevantes de los países de tránsito. En primer lugar son relativamente escasos y ligados en su mayor parte a los principales centros financieros internacionales. Se trata de un selecto grupo capaz de concentrar y posteriormente canalizar los flujos financieros internacionales hacia España (OCDE, 2013). Proceden mayoritariamente de la UE y, con excepción de EE UU, el resto de áreas geográficas apenas tiene una representación significativa. Los países que absorben un mayor flujo de inversión son Países Bajos, Italia, Luxemburgo y Francia, con un 57,6\% del valor global de la misma. Dicho de otra forma, más de la mitad de las inversiones realizadas en España desde el exterior se canalizan a través de estos cuatro Estados (Mapa 1).

En segundo lugar, no es de extrañar la presencia de Italia y Francia como principales puntos de inversión, que puede obedecer entre otras causas a factores de proximidad espacial, un elemento que permite un mejor conocimiento de la economía y las oportunidades de inversión en España. Resulta significativo que la práctica totalidad $(98,15 \%)$ del capital canalizado desde Italia tiene su origen último en el país transalpino; lo mismo ocurre con Francia, que cuenta con un capital propio del $84,15 \%$.

Sin embargo, los casos de Luxemburgo y Países Bajos se encuentran ligados a una lógica diferente, vinculada tal vez a las ventajas fiscales derivadas de algunas figuras normativas ligadas en buena parte a los convenios de doble imposición, o al papel que desempeñan determinadas sociedades holandesas en los movimientos internacionales de capital. Si Francia e Italia invierten en España con fondos fundamentalmente propios, Luxemburgo y Países Bajos lo hacen en su mayor parte con capital de terceros países. Frente a magnitudes cercanas al $100 \%$ de Italia y $80 \%$ de Francia sólo el $41,23 \%$ de las inversiones emitidas desde Luxemburgo se realiza con capital luxemburgués. La cifra disminuye aún más en el caso de Países Bajos que apenas cuenta con el $14,01 \%$ de capital propio. 
Mapa 1. Países de tránsito de la IED en España

(según el valor de su stock en millones de euros, 2012)

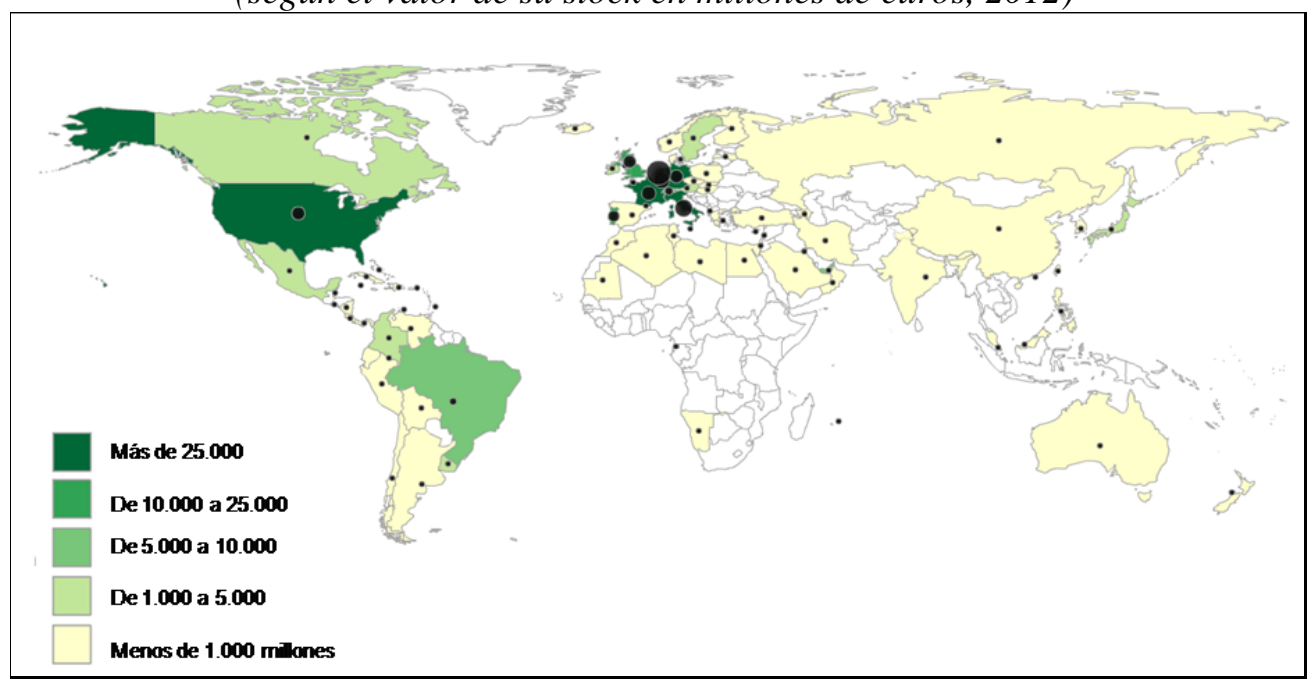

Fuente: DataInvex al 4/08/2014 y elaboración propia.

Es evidente el papel que juegan en este proceso los paraísos fiscales, centros financieros offshore y determinadas legislaciones fiscales favorables en algunos países europeos, como son los casos de Luxemburgo y Países Bajos. Son dos Estados claves para España en los movimientos financieros internacionales y constituyen una puerta de entrada de capital utilizando en ocasiones sofisticados sistemas de ingeniería fiscal o formando parte como países de tránsito ligados a procesos de inversión circular procedente de España ${ }^{5}$. Resulta significativo que el $90 \%$ de las empresas que cotizan en el IBEX-35 tienen sociedades localizadas en estos países.

El movimiento espacial de capital tiene por tanto un comportamiento diferencial según sea el país de tránsito por donde circula. Su ruta es más compleja cuando en el circuito interviene algún paraíso fiscal que el desarrollado entre dos Estados donde las condiciones tributarias son similares. Por tanto, la ruta espacial que siguen los flujos entre España y países como Francia, Alemania o Italia son desde el punto de vista de la movilidad territorial más sencillos que aquellos que se canalizan a través de Países Bajos, Luxemburgo, Delaware o Guersney.

Una análisis de las magnitudes de inversión permite realizar una clasificación de la cartografía financiera española en cuatros grandes grupos. Los movimientos más importantes son los flujos de primer nivel, con inversiones que superan los 10.000 millones de euros en cuanto al valor de su stock. Este grupo conforma la principal

\footnotetext{
${ }^{5}$ Denominadas en el argot financiero como "sándwich holandés" o "doble irlandés".
} 
entrada de capital extranjero en España y mantiene importantes lazos de carácter estratégico. La procedencia del capital puede ser propia (como es el caso de EE UU, Italia, Francia Reino Unido, Alemania o México entre otros) o canaliza fondos de terceros (Países Bajos y Luxemburgo).

Las inversiones de segundo nivel cuentan stocks acumulados por un valor que oscila entre 5.000 y 10.000 millones. Algunas de ellas corresponden a flujos financieros entre países anteriormente destacados, a los que habría que sumar otros Estados intermedios. Los flujos del tercer nivel se sitúan entre 1.000 y 5.000 millones. Finalmente, los flujos de cuarto nivel se corresponden con inversiones inferiores a 1.000 millones - a partir de un mínimo de 100 millones-.

Las diferencias en la circulación espacial del capital se ven reflejadas en el comportamiento de la inversión emitida desde Países Bajos e Italia, dos de los mayores inversores en España. En el primer caso existe un elevado nivel de diversificación de la procedencia del capital. Sólo el 14,01\% de la inversión registrada desde Países Bajos procede de allí, el resto es capital procedente de terceros países. Llama la atención que México es el mayor inversor en cuanto a país de origen, con un stock valorado en 16.884 millones de euros, de los cuales una parte importante está ligada a la participación de grandes empresas mexicanas en el sector energético español, como es el caso de PEMEX en REPSOL.

Gráfico 3. Origen de las mayores inversiones declaradas desde Países Bajos

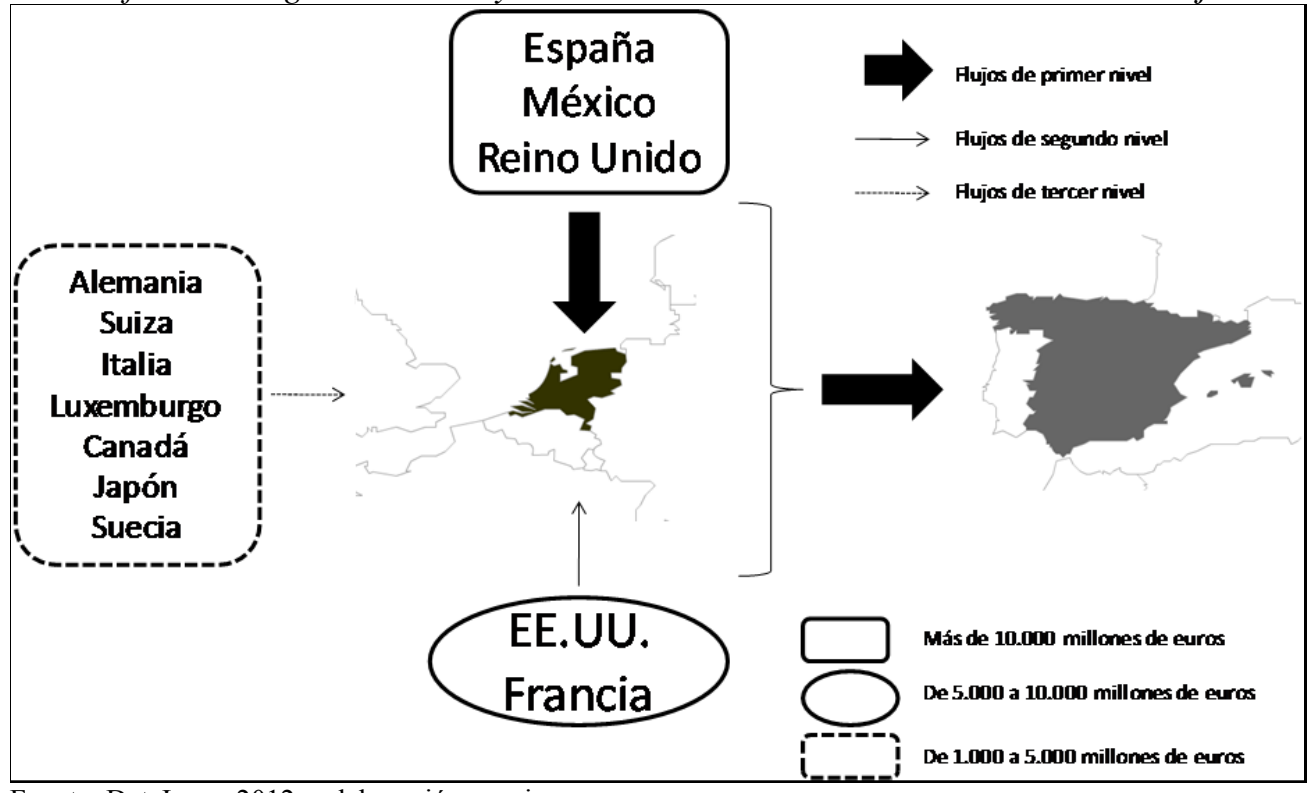

Fuente: DataInvex 2012 y elaboración propia. 
Es también significativo que España sea el segundo país de origen que canaliza fondos a través de Países Bajos, por valor de 13.445 millones. Parece ser que los inversores españoles, especialmente las grandes empresas, utilizan sociedades allí constituidas para trasvasar sus beneficios y pagar allí una parte de sus impuestos, detrayendo así sus ingresos a la Hacienda española. Es probable que la corrección de este fenómeno pudiera contribuir a la reducción del déficit público, así como una mejor distribución de las cargas fiscales, que están mayoritariamente soportadas por el resto de la sociedad.

México, España y Reino Unido son los mayores inversores, pero el resto del capital se encuentra diseminado en torno a otros países (como es el caso de EE UU, Francia o Alemania entre otros) que canalizan una parte significativa de sus inversiones a través de Países Bajos (Gráfico 3).

El caso de Italia es opuesto al anterior. Aunque es también un gran inversor de capital en España, no funciona como país de tránsito real. El 98,15\% de las inversiones proceden de capital de origen italiano, las aportaciones del resto de los países son por tanto prácticamente insignificantes ${ }^{6}$ (Gráfico 4).

\section{Gráfico 4. Origen de las mayores inversiones declaradas desde Italia}

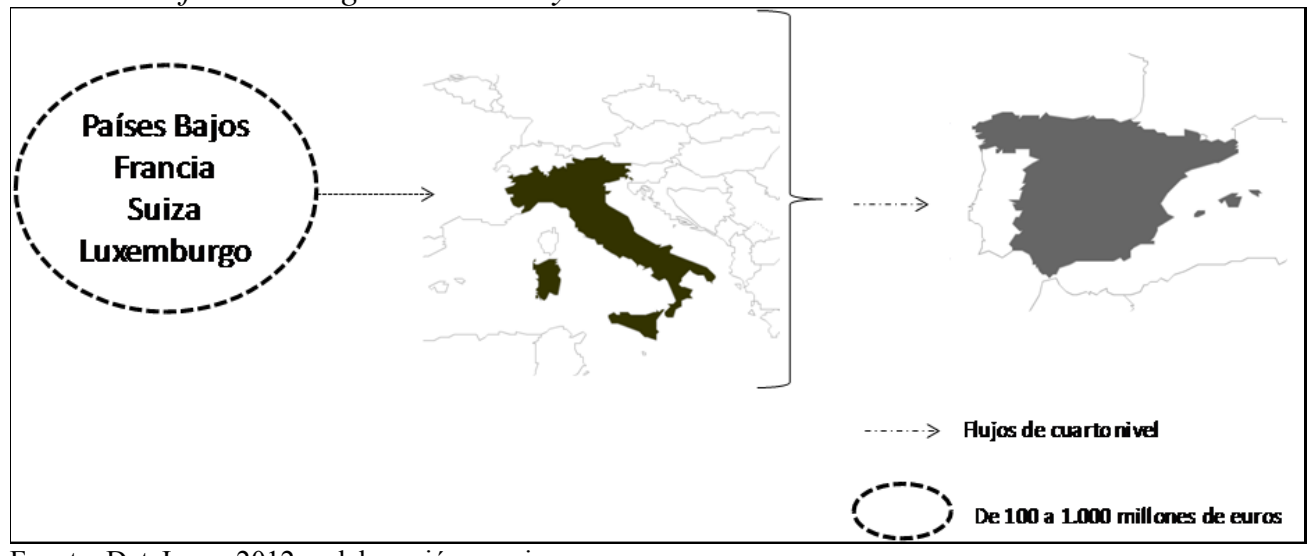

Fuente: DataInvex 2012 y elaboración propia.

Algo similar ocurre con los casos de Luxemburgo y Francia. El nivel de diversificación del capital de origen gestionado desde el Gran Ducado supone un 41,23\% del valor de stock y procede de empresas allí localizadas. Esto da idea de la existencia de una red financiera que tiene en ambos casos una estructura diferente. Otro

\footnotetext{
${ }^{6}$ Países Bajos es el mayor inversor de origen que emite capital desde Italia y apenas representa el $0,42 \%$ del valor total de la misma.
} 
aspecto importante es la estrecha relación que existe entre el capital de origen norteamericano y las sociedades financieras luxemburguesas. El 30,53\% de todo el capital que circula por Luxemburgo con destino a España procede de inversores procedentes de EE UU (Gráfico 5).

Gráfico 5. Origen de las mayores inversiones declaradas desde Luxemburgo

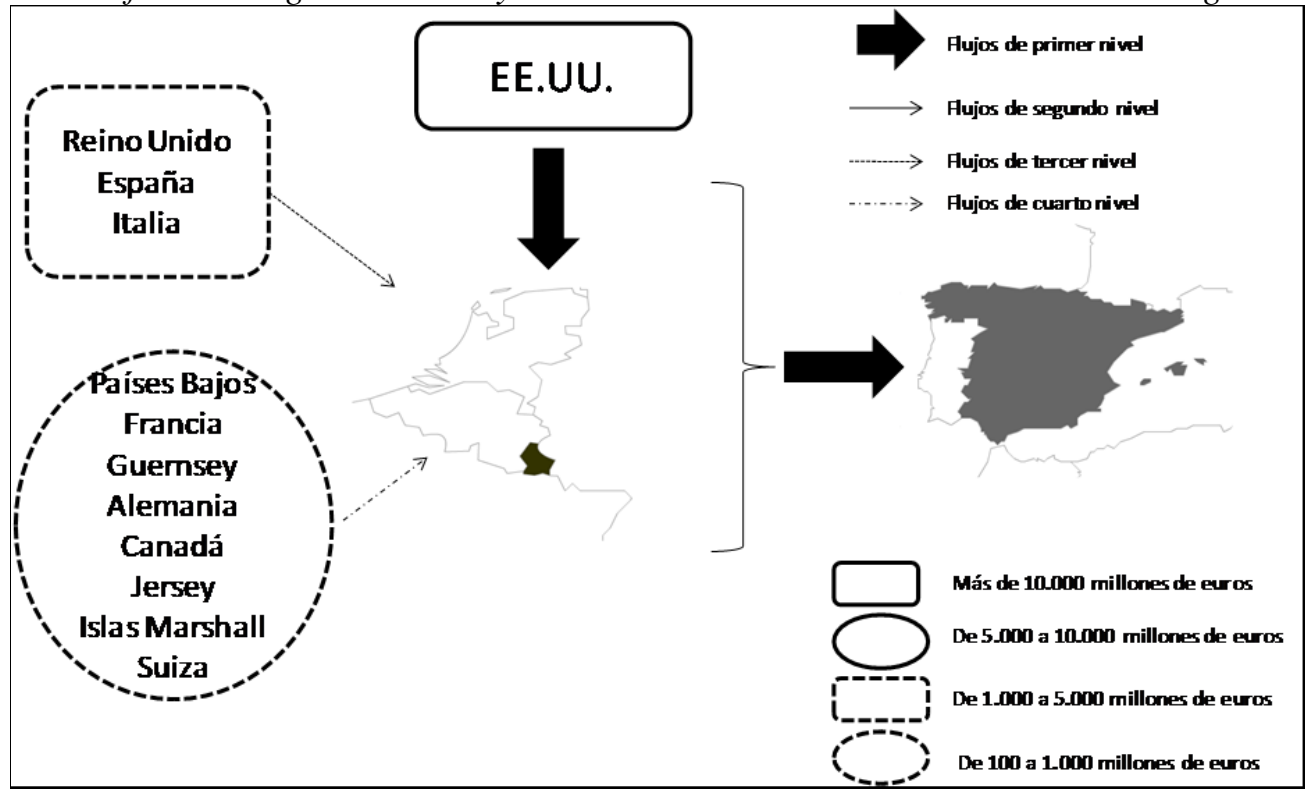

Fuente: DataInvex 2012 y elaboración propia.

Un segundo elemento llamativo es la presencia de inversores localizados en paraísos fiscales que utilizan al Gran Ducado para comprar en España. Aunque tienen una presencia residual, el papel que juegan los bailiazgos de Jersey y Guernsey, espacios ligados tradicionalmente a la City de Londres; o las Islas Marshall, vinculadas a sociedades financieras de EE UU complican el estudio espacial, ya que para la transacción de determinadas inversiones no es suficiente el paso por un único paraíso fiscal, sino que intervienen al menos dos. Los datos no permiten reflejar cuál sería el lugar de origen final de los fondos gestionados desde estos centros financieros internacionales.

Por otro lado, EE UU es el mayor inversor en España (Gráfico 6), aunque casi todo el valor de su capital $(95,34 \%)$ procede de empresas allí localizadas. No es por tanto para España un país de intermediación y funciona mayoritariamente con fondos propios. Francia, México y Antillas Neerlandesas son países de origen que canalizan la inversión en España a través de EE UU, aunque el valor de sus stocks es testimonial. 
Sí es significativa la presencia de una pequeña inversión de Rusia en España a través de empresas estadounidenses. La importancia no es tanto por su valor, apenas 121 millones de euros, sino por ser el único rastro reseñable de inversión de este país en España ${ }^{7}$.

Gráfico 6. Origen de las mayores inversiones declaradas desde EE UU

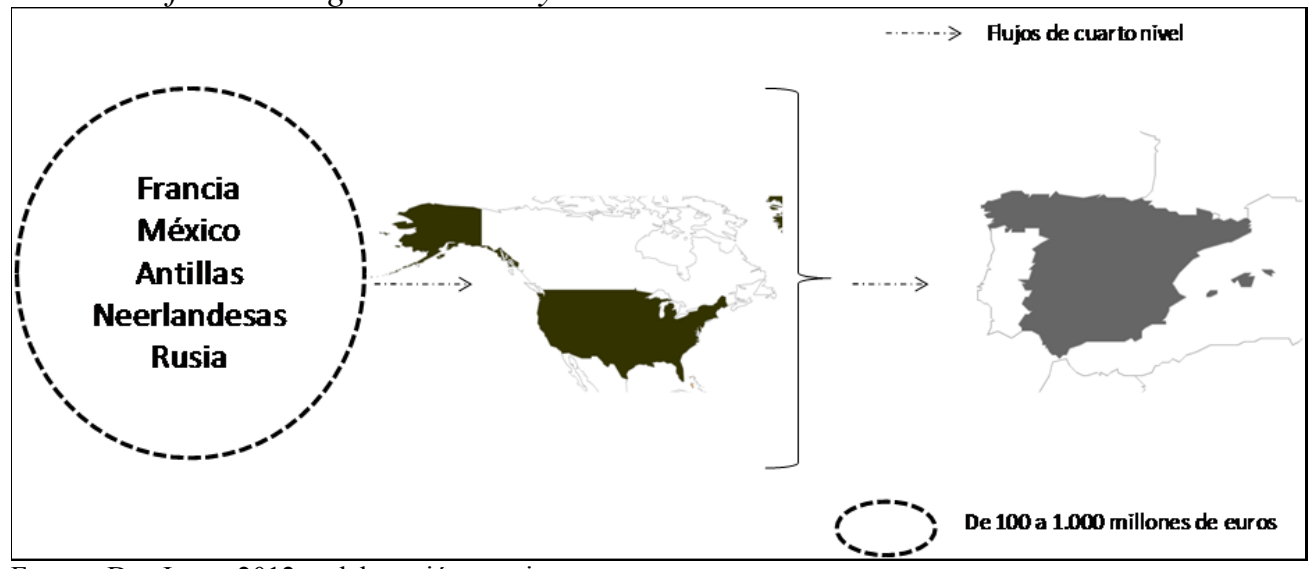

Fuente: DataInvex 2012 y elaboración propia.

Alemania y Reino Unido completan el mapa de países por donde transita el capital que llega a España. Ambos casos tienen un comportamiento similar en cuanto a las grandes magnitudes. El origen final de los fondos procede de inversores radicados en ambos Estados (86,86\% en Alemania y $82,02 \%$ en Reino Unido). El resto del capital que transita por Alemania con destino a España procede principalmente de EE UU (6,99\%), mientras que el capital que transcurre por la City procede en su mayor parte de Israel y de EE UU (Gráfico 7).

\section{Estructura espacial de las cadenas financieras de inversión: países de origen y sectores de inversión}

El país de origen determina la propiedad final conocida de la inversión. Desde el punto de vista geopolítico, estos espacios inversores son estratégicos para España, ya que le permiten obtener una fuente de financiación externa clave para su estabilidad económica. Aunque se ha registrado IED desde noventa y siete países, existe

\footnotetext{
${ }^{7}$ La escasa inversión se concentra en la adquisición de patrimonio inmobiliario en el litoral español, un aspecto secundario en las grandes magnitudes de la IED.
} 
un fuerte proceso espacial de concentración de su valor en torno a un selecto conjunto de siete Estados que representan el 68,09\% del valor total registrado, una cifra importante aunque menos acusada que el de los países intermedios $(78,82 \%)$.

Los países que concentran la mayor parte de la inversión son los mismos que los registrados según su valor de tránsito, con excepción de México, el sexto mayor inversor en España con un 5,38\% del total. Por el contrario, su orden varía; los mayores inversores en España proceden de Estados Unidos, Italia y Francia, que absorben el 39,56\% del valor total del stock. Desaparece de estos puestos Países Bajos, que no destaca como país inversor aunque, tal y como se vio con anterioridad, era el principal país de tránsito.

\section{Gráfico 7. Origen de las mayores inversiones declaradas desde Alemania}

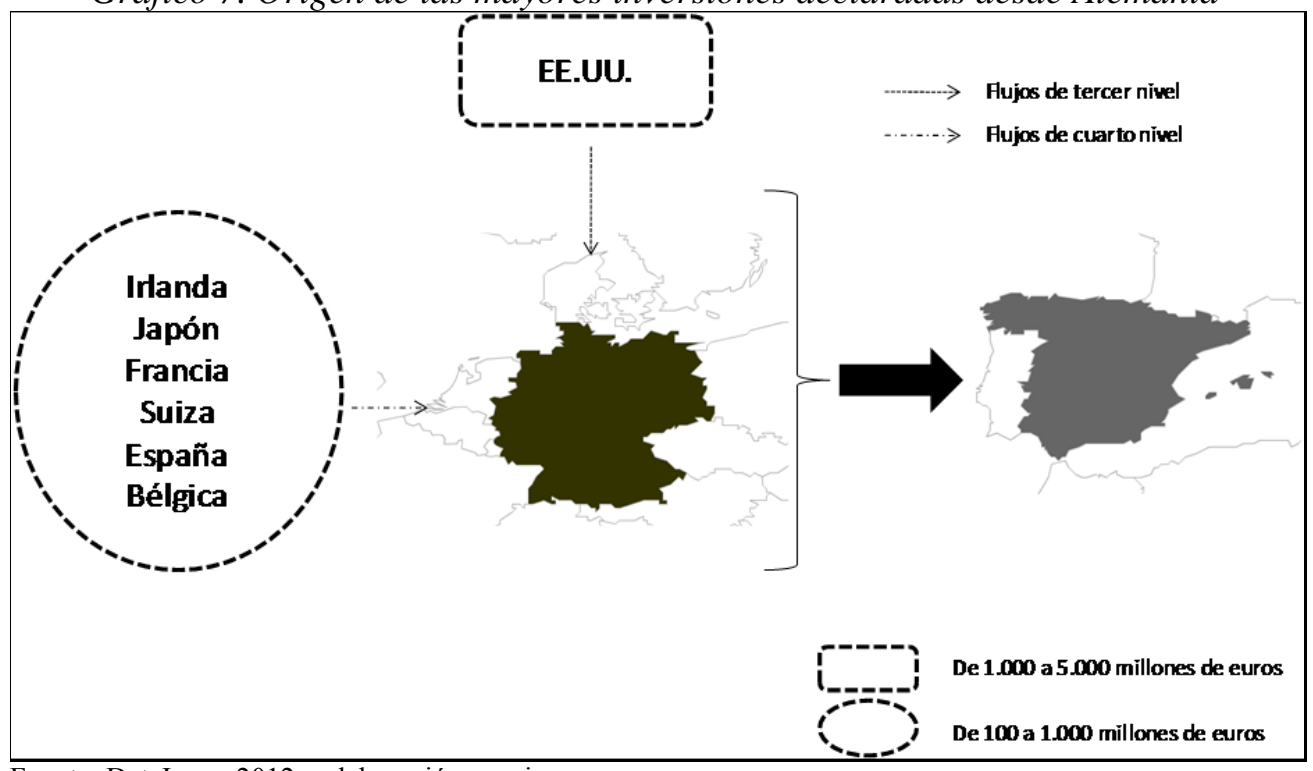

Fuente: DataInvex 2012 y elaboración propia.

Existen países estratégicos que transfieren flujos de capital a España por valor superior al que se genera como punto de origen. Funcionan como nodo de inversiones dentro de la red financiera de distribución de capital (Vázquez, 2009). El caso más evidente es el de Países Bajos, que como ya se ha visto con anterioridad, es el primer país de tránsito con inversiones valoradas en 90.684 millones de euros. Sin embargo, cuando se analiza la inversión como país origen esta cifra disminuye hasta los 14.736 millones, una cifra sensiblemente inferior. Lo mismo ocurre con Luxemburgo, que tiene invertido en España activos por valor de 19.241 millones, la mitad del valor que gestiona como espacio de tránsito (39.467 millones). 
Gráfico 8. Flujos de inversión con origen en EE UU y destino España

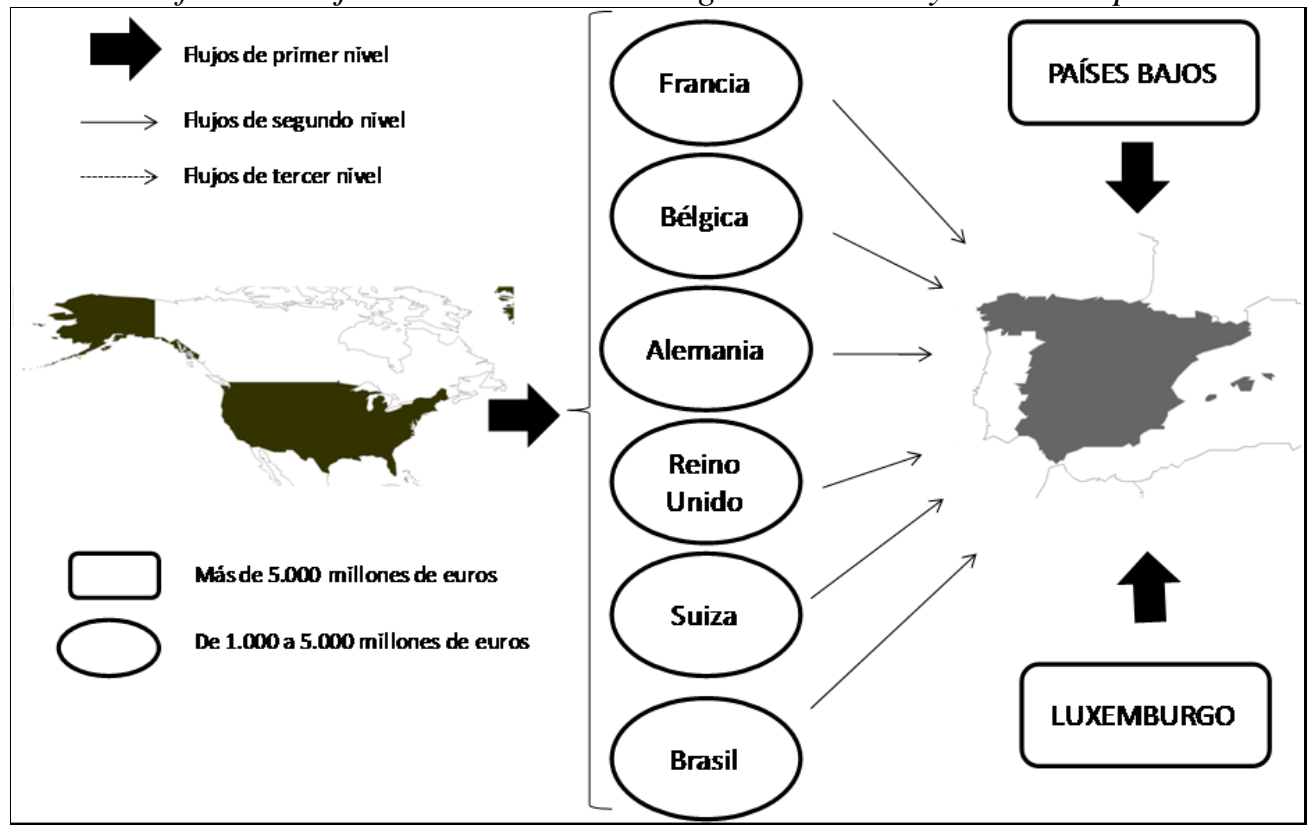

Fuente: DataInvex 2012 y elaboración propia.

Otro rasgo característico de este fenómeno es que parece existir una relación directa entre la utilización de terceros para la canalización de las inversiones y su lejanía geográfica. Desde la posición de los centros financieros de rango global, España ocupa un espacio de segundo orden que carece de lazos financieros consolidados con las principales economías emergentes de Asia. Estos tienden a utilizar intermediarios para canalizar sus inversiones en España, mientras que los países europeos vecinos, mejores conocedores del mercado español, suelen hacerlo de forma directa. En términos generales se puede afirmar que las principales economías europeas continentales son más proclives a invertir directamente en España, mientras que las procedentes de América y Asia lo hacen a través de sociedades radicadas en Luxemburgo y Países Bajos.

La importancia de los flujos por donde circula el capital queda reflejada en los datos de Estados Unidos. Tiene una cartera de inversiones muy diversificada por valor de 57.308 millones de los que sólo la mitad (26.932 millones), se han gestionado directamente desde allí. El resto del capital lo ha hecho a través de terceros, especialmente Países Bajos y Luxemburgo, antes de llegar a España (Gráfico 8). Fabricación de vehículos $(11,68 \%)$, comercio al por mayor $(11,05 \%)$, industria 
química $(10,67 \%)$ y metalurgia $(8,04 \%)$ son los sectores que concentran la mayor parte de la inversión ${ }^{8}$. Resulta significativo que tres de los cuatro mayores sectores con mayor presencia de capital norteamericano en España está ligado al sector industrial.

No ocurre lo mismo con los casos italiano, francés y alemán, que parecen no utilizar de manera tan significativa a terceros para canalizar las inversiones. En el caso de Italia, segundo mayor inversor en España, tiende a invertir directamente en España sin necesidad de terceros. La utilización de países intermedios es escasa y concentrada en Países Bajos y Luxemburgo (Gráfico 9). Al contrario de lo que ocurre con Estados Unidos no hay diversificación de la IED, que se concentra casi exclusivamente en el sector de la energía eléctrica, que representa el $81,30 \%$ de la inversión total en España. La mayor parte de la misma corresponde con la adquisición por parte de la compañía italiana ENEL del 71,14\% de capital de ENDESA.

\section{Gráfico 9. Flujos de inversión con origen en Italia y destino España}

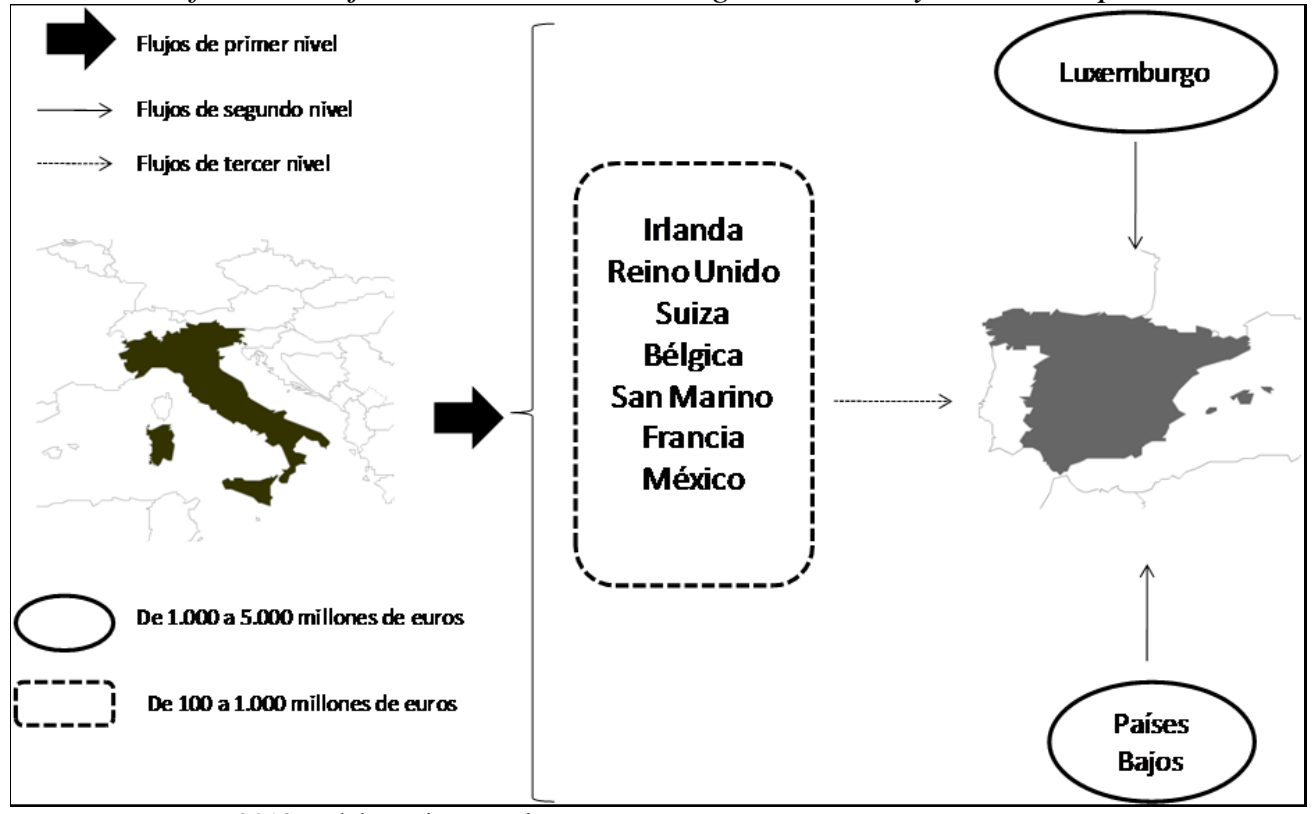

Fuente: DataInvex 2012 y elaboración propia.

\footnotetext{
${ }^{8}$ Destacan las inversiones de grandes multinacionales industriales y de la alimentación en España como Pepsico, Kellogs, Procter \& Gamble o Foster Wheeler entre otras.
} 
Francia tiene numerosos y tradicionales lazos de inversión en el mercado financiero español. Lidera la deuda pública y es el tercero en lo que respecta a la IED. Al igual que ocurre con Italia, los datos analizados apuntan a que la mayor parte del capital francés se invierte directamente sin pasar por espacios de tránsito. El único intermediario significativo son los Países Bajos, el resto gestiona carteras por un valor inferior en el mejor de los casos, a 1.000 millones de euros (Gráfico 10). La inversión se concentra principalmente en comercio minorista ${ }^{9}(14,97 \%)$ y fabricación de productos minerales no metálicos $(11,68 \%)$. Servicios financieros, distribución de agua, o fabricación de vehículos son otros sectores con una cierta presencia.

\section{Gráfico 10. Flujos de inversión con origen en Francia y destino España}

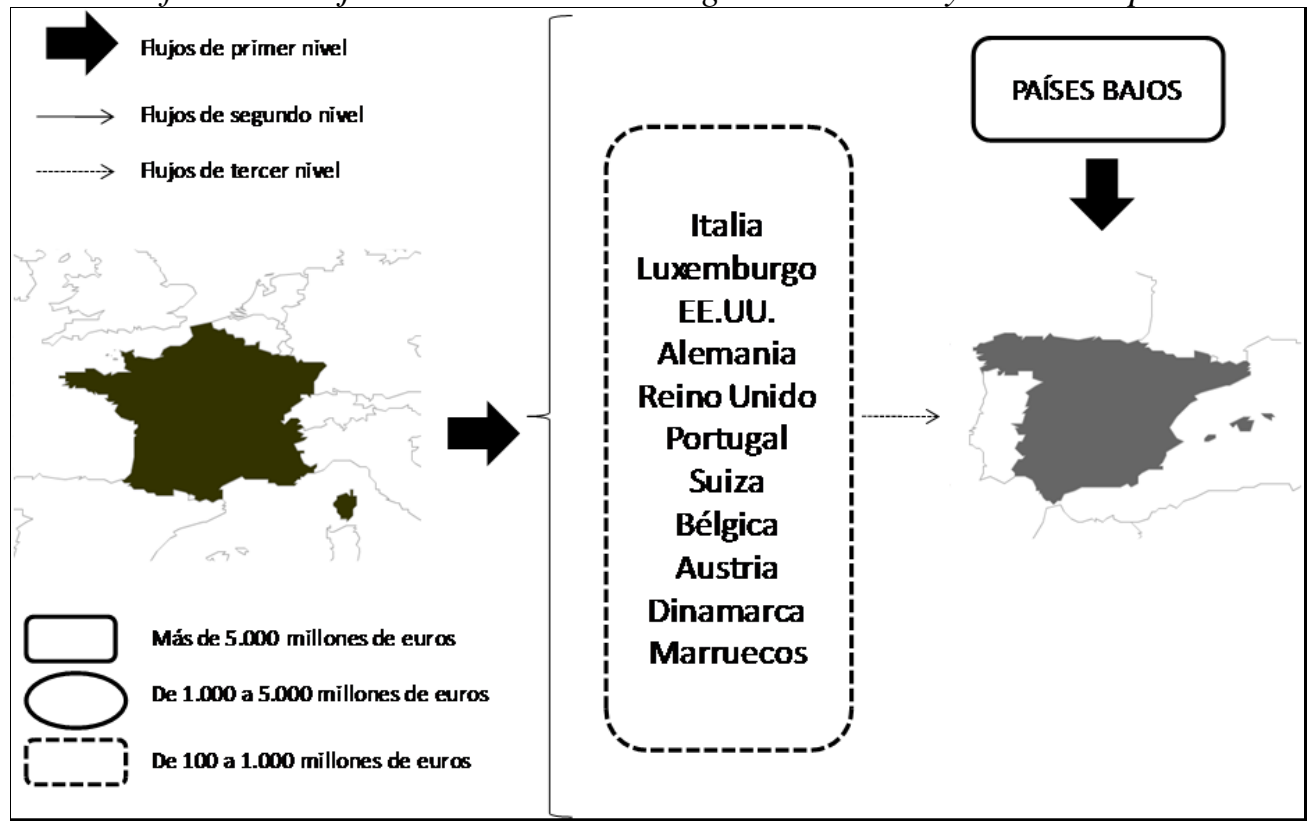

Fuente: DataInvex 2012 y elaboración propia.

En lo que respecta a Reino Unido, la lógica de la IED en España es similar a la que utiliza EE UU y diferente al resto de las grandes economías europeas. Aunque con un volumen de inversión inferior, la economía británica utiliza también a intermediarios financieros de Países Bajos y Luxemburgo para canalizar una parte importante de su cartera (Gráfico 11). La compleja estructura financiera que existe

\footnotetext{
${ }^{9}$ Especialmente en grandes superficies comerciales como es el caso de Carrefour, Alcampo o Decathlon, entre otras.
} 
en el Reino Unido se manifiesta en el papel que juegan determinados paraísos fiscales (Gibraltar, Islas Vírgenes, Isla de Man o Guernsey) en el itinerario espacial de inversiones en España. La diversidad geográfica contrasta con la relativa especialización en los sectores de tabaco $(22,58 \%)$ y telecomunicaciones $(18,65 \%)^{10}$.

\section{Gráfico 11. Flujos de inversión con origen en Reino Unido y destino España}

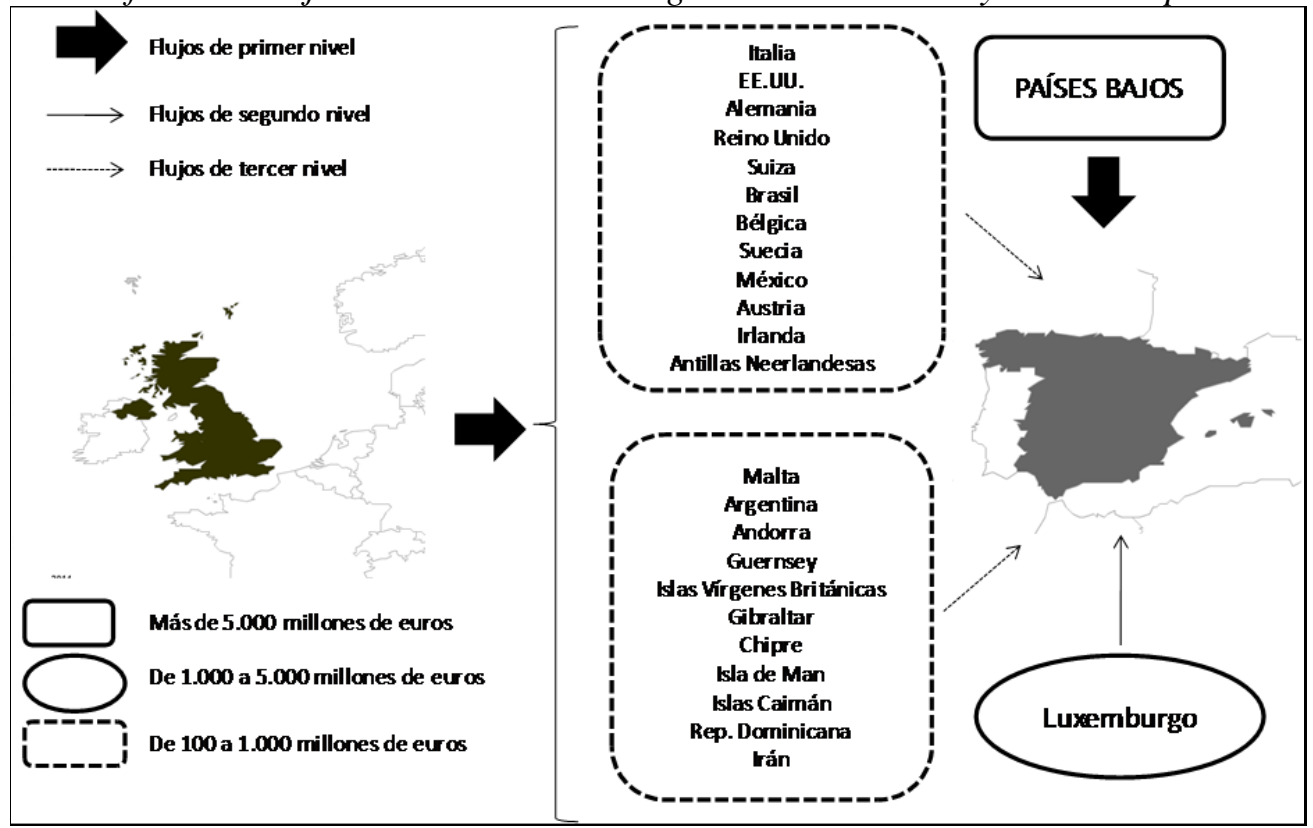

Fuente: DataInvex 2012 y elaboración propia.

Alemania sigue el mismo patrón que Francia e Italia. El 76,56\% de las inversiones se realizan directamente en España, el resto se realiza a través de Países Bajos, que gestiona un 16,57\% de la inversión (Gráfico 12). La mitad se concentra en cuatro sectores de actividad: fabricación de vehículos (18,03\%), energía eléctrica $(14,08 \%)$, productos farmacéuticos $(8,14 \%)$ y comercio al por mayor $(9,65 \%)^{11}$. Repite por tanto la misma lógica inversora en España que la existente en EE UU. Concentración del capital en sectores industriales estratégicos y la distribución comercial.

\footnotetext{
${ }^{10}$ Destacan los casos de Imperial Tobacco, propietaria de Altadis, o Vodafone.

${ }^{11}$ Destacan las grandes multinacionales alemanas en diferentes ramas de actividad industrial, como es el caso del sector de la automoción (Mercedes, Audi, BMW); químico (BASF) o eléctrico (E.ON).
} 
Gráfico 12. Flujos de inversión con origen en Alemania y destino España

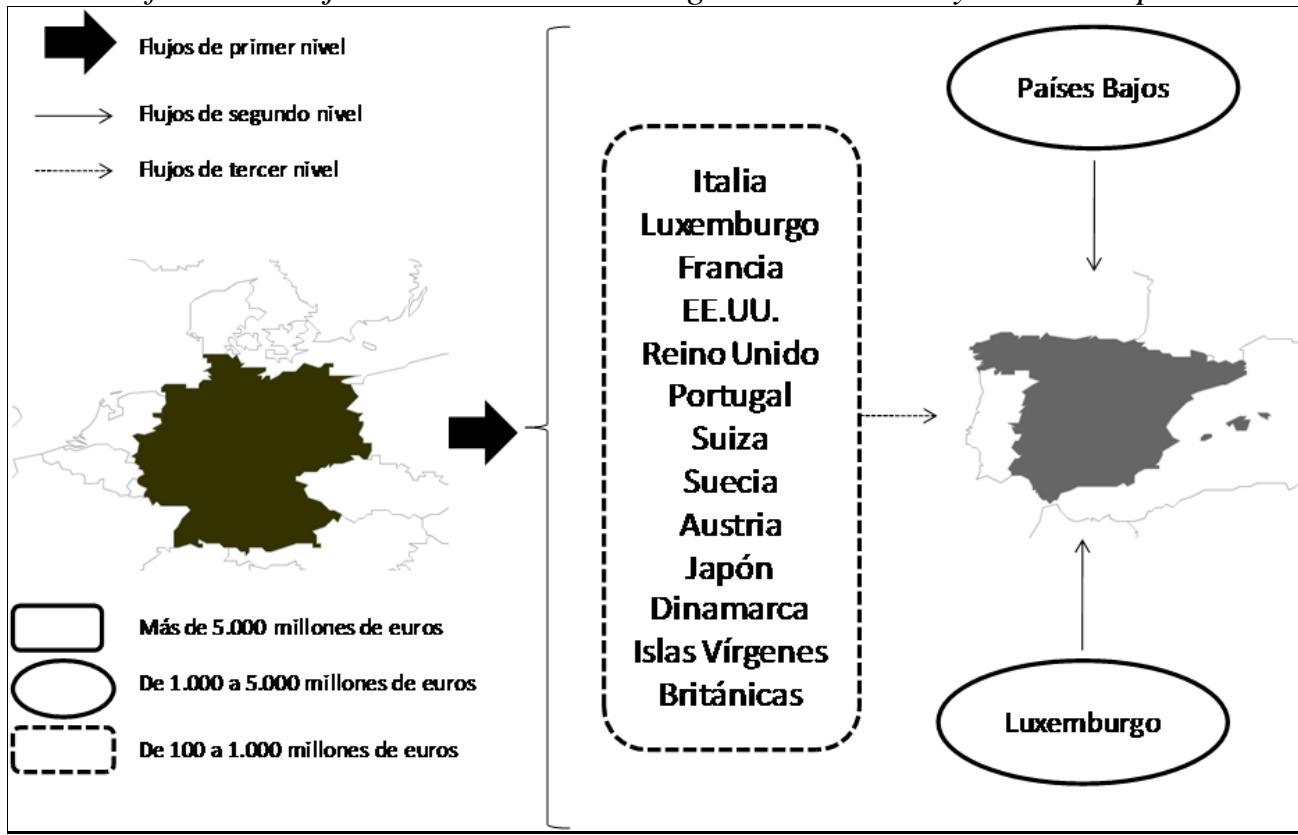

Fuente: DataInvex 2012 y elaboración propia.

Una cuestión que llama poderosamente la atención es que España es uno de los mayores inversores extranjeros en España. En apariencia podría carecer de sentido que una empresa o inversor radicado en un país invierta en el mismo a través de terceros Estados, sin embargo el sistema de funcionamiento de los procesos de movilidad del capital entre países genera este tipo de movimientos financieros denominados como "inversión circular" (round trip). Prats y Marín (2010) plantean que este fenómeno de deslocalización fiscal se desarrolla a partir de tres actores principales: un inversor localizado en España, una sociedad intermedia - normalmente en forma de holding - situada en otro espacio, y que tiene como principal función la gestión de las participaciones del inversor. Normalmente estas suelen estar localizadas en Luxemburgo o Países Bajos al tener un régimen de exención o mejores condiciones sobre dividendos o plusvalías de fuente extranjera. El tercer agente necesario es una sociedad localizada en España que esté participada por el primer inversor. Este sistemas de ingeniería fiscal permite un flujo fluido de entrada y salida del capital dirigido fundamentalmente a pagar menos impuestos (Da Costa, 2011). Movilidad de capital y exenciones fiscales son por tanto dos conceptos interrelacionados y ligados a la geografía financiera española.

La inversión circular por IED en España ascendió en 2012 a 18.234 millones de euros, y se concentra casi en su totalidad en Países Bajos con 13.445 millones enviados a ese destino para su posterior regreso a España. Luxemburgo (1.829 
millones) y Brasil (1.044) son los siguientes destinos en orden de importancia, aunque a una distancia sustancial. La concentración de las inversiones no es solo una cuestión espacial, afecta también a los sectores de actividad. Resulta significativo que el $48,77 \%$ de la salida de capitales al exterior está ligada al sector de ingeniería civil (constructoras de grandes infraestructuras y equipamientos) y servicios de intermediación financiera (banca), es decir, en los protagonistas de los procesos especulativos del boom inmobiliario.

Este proceso permite explicar que la participación de los paraísos financieros como foco de inversión en España no ha dejado de aumentar en los últimos años, y su influencia en los diferentes sectores de actividad está claramente ligada a algunos muy determinados.

Existe una concentración de inversiones a través de Empresas Tenedoras de Valores Extranjeros (ETVE), que tienen un elevado componente especulativo, procedentes de paraísos fiscales como espacio de origen. Parece existir una correlación entre inversiones procedentes de espacios offshore y la utilización de ETVE como figura societaria ligada a la obtención de numerosas ventajas fiscales. Utilizando estrategias de ingeniería fiscal ligadas a figuras legales como son los convenios de doble tributación, la opacidad de determinados paraísos fiscales o la existencia en España de la figura de ETVE, los flujos espaciales de capital desarrollan un itinerario a través de diversos puntos que tiene como estrategia final minimizar cuando no evitar el pago de impuestos de las grandes empresas españolas y extranjeras.

El nivel de especialización es algo inferior cuando se analiza la distribución de la IED por sectores de actividad. Un tercio de su valor se concentra en tres sectores de actividad: consumo de energía $(17,34 \%)$, fabricación de productos minerales $(7,76 \%)$ y comercio al por mayor $(6,54 \%)$. Por zonas geográficas la inversión en suministro energético y en menor medida comercio al por mayor procede principalmente de Europa. Por el contrario, la inversión en industria manufacturera procede en su mayor parte de los países emergentes de Latinoamérica. Industria química, metalurgia o comercio al por mayor son otros sectores donde tiene una cierta presencia las inversiones procedentes de América del Norte (Gráfico 13).

El suministro de energía eléctrica supone la mayor inversión extranjera en España y requiere por su importancia estratégica un mayor análisis. El valor total de sus stocks alcanza los 62.691 millones, el mayor con diferencia de toda España. Más de la mitad procede de Italia, que mantiene inversiones en España en suministro eléctrico por valor de 39.514 millones de euros. Esto supone el 10,92\% de toda la IED registrada en España y, como se ha comentado con anterioridad, la mayor parte de la misma se encuentra vinculada a la adquisición en 2009 de ENDESA por parte de ENEL. Aunque no adquiere las proporciones del caso italiano, Portugal mantiene también una inversión muy significativa en el sector eléctrico español, que en 2012 
alcanza un valor de 15.386 millones de euros, un 4,25\% de toda la IED en España. La participación de Qatar Holding en Iberdrola o de Temasek ${ }^{12}$ en REPSOL, son otros ejemplos de este proceso de inversión de capital extranjero en el sector energético.

Gráfico 13. Distribución geográfica de los principales sectores de actividad en países de origen (según el valor de sus stocks en 2012)

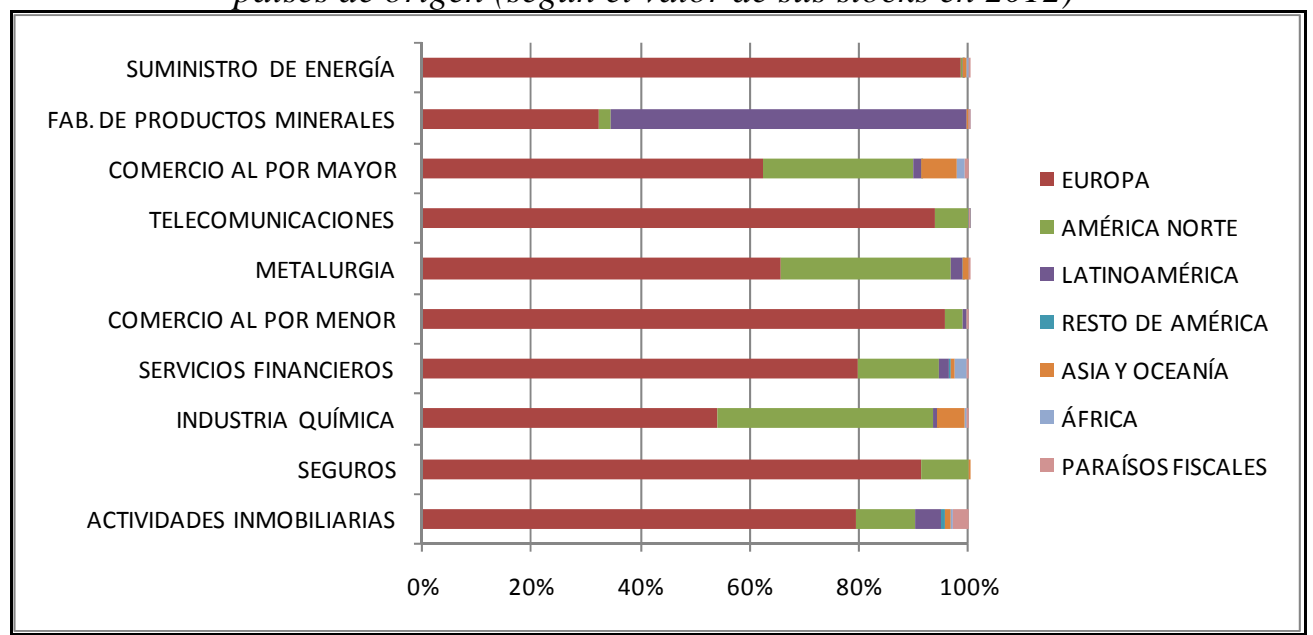

Fuente: DataInvex y elaboración propia.

La distribución por sectores revela la existencia de asimetrías importantes en la distribución de la IED. Existe un importante sesgo de la inversión que se encuentra ligado a determinados sectores estratégicos. Junto al de la energía eléctrica, el sector industrial y de comercio al por mayor absorbe también una proporción importante de la inversión. México concentra el 59,51\% de la inversión en industria de productos no metálicos, el segundo sector más importante, con un valor de stock de 16.693 millones de euros en 2012. Una parte importante de la misma está ligada a la presencia de la cementera CEMEX ${ }^{13}$.

Finalmente, en lo que respecta al comercio al por mayor, existe una mayor dispersión espacial de los centros de inversión. El 61,53\% procede de seis países diferentes (Brasil, EE UU, Francia, Luxemburgo, Países Bajos y Reino Unido); Estados Unidos, con un $26,78 \%$ lidera en este sector.

\footnotetext{
${ }^{12}$ Uno de los mayores fondos soberanos de Singapur.

${ }^{13}$ La evolución de los datos de flujos de inversión pone de manifiesto que México está incrementando de manera sensible su participación en empresas claves, como es el caso de Campofrío o los Bancos Sabadell y Popular.
} 


\section{Conclusiones}

La crisis financiera ha modificado la circulación espacial de los flujos internacionales de capital, y está generando un impacto desigual en los territorios por donde transita. Los efectos son múltiples, tanto desde el punto de vista cuantitativo (inversiones en distribución comercial), como cualitativo (proporción de capital extranjero en sectores estratégicos). Favorece en la mayor parte de los casos a los países de tránsito, nudos financieros internacionales especializados en su gestión internacional, y desarrolla en su interior un importante tejido de sociedades financieras que aportan una parte sustancial del PIB regional.

No ocurre lo mismo con los puntos de destino final, sujetos en primer lugar a una mayor arbitrariedad derivada de las condiciones temporales del mercado, especialmente en aquellos productos que están ligados a inversiones con un elevado nivel especulativo.

La tipología espacial de inversores en España podría establecerse en torno a tres grandes grupos. El primero de ellos es un modelo de inversión directa, sin intermediarios. Es utilizado habitualmente por las principales economías europeas (Francia, Italia y Alemania) y parece estar asociado a elementos de proximidad geográfica y a un mejor conocimiento de la economía española por parte de los inversores residentes en estos países.

El segundo modelo es más complejo desde el punto de vista de los flujos espaciales, y está basado en la utilización de países intermedios (muchos de ellos paraísos fiscales y centros internacionales offshore) que concentran las inversiones que se dirigen a España. Los dos principales países de tránsito son Luxemburgo y Países Bajos y el origen de sus inversiones procede principalmente de Estados Unidos, México, Reino Unido y la propia España.

Las ventajas fiscales de los países de tránsito en los movimientos internacionales del capital parecen explicar, al menos en parte, este sistema espacial. Las operaciones de ingeniería fiscal organizadas por grandes empresas transnacionales, y gestionadas por las principales consultoras internacionales están en el fondo de este proceso. Existe por tanto una tendencia a utilizar mecanismos espaciales más complejos en la inversión procedente de Asia, EE UU y Reino Unido, frente a los utilizados por Francia, Alemania o Italia, donde las inversiones son más directas.

El tercer mecanismo está ligado a la salida de capitales al exterior generados por inversores españoles que utilizan a estos países inmediatos para pagar menos impuestos en España. Este proceso de inversión circular es cuantitativamente importante y sitúa a nuestro país como noveno inversor "exterior". Casi la mitad de las inversiones de estas sociedades, que utilizan centros financieros offshore para disminuir o simplemente eludir el pago de impuestos, están vinculadas a destacadas empresas españolas de ingeniería civil y del sector bancario que han estado en el epicentro de la crisis financiera. 
La sincronización de los mercados financieros internacionales ha supuesto numerosas ventajas en etapas de crecimiento económico, pero tal vez sería interesante investigar si se ha producido una deslocalización parcial de la crisis financiera, facilitando la propagación espacial de la misma desde los espacios centrales a los periféricos, concentrando e intensificando allí el impacto global de la misma.

Otro aspecto importante que queda pendiente de una investigación en profundidad es el impacto espacial que tiene la IED en España. Es plausible pensar que la dirección, sentido e intensidad de los flujos de capital tienen una importancia determinante en los espacios receptores de la misma, pero es necesario demostrarlo y establecer su incidencia cuantitativa y cualitativa. Posiblemente, las Comunidades Autónomas españolas que reciben mayor flujo de capital pueden tener una estructura económica diferente a la que se da en aquellos espacios donde la inversión es sustancialmente inferior. Determinar los circuitos de paso del capital y su impacto por sectores de actividad es clave para comprender algunas de las diferencias regionales existentes.

\section{Bibliografía}

Agnew, John (2012) "Putting politics into economic geography", en T. J. Barnes, J. Peck y E. Sheppard (eds.) The Wiley-Blackwell Companion to Economic Geography. Chichester: John Wiley \& Sons Ltd, 567-580.

Asgharian, Hossein; Hess, Wolfgang, y Liu, Lu (2013) "A Spatial Analysis of International Stock Market Linkages". Journal of Banking and Finance, vol. 37, núm. 12, 4738-4754.

Baldacci, Emanuele; Dell'Erba, Salvatore, y Poghosyan, Tigran (2011) Spatial Spillovers in Emerging Market Spreads. International Monetary Fund Working Papers 11/221.

Chinazzi, Matteo; Fagiolo, Giorgio; Reyes, Javier, y Schiavo, Stefano (2012) "PostMortem Examination of the International Financial Network". Journal of Economic Dynamics and Control, vol. 37, núm. 8, 1692-1713.

Da Costa, Emilia (2011) "Las estructuras offshore como un mecanismo de planificación y deslocalización fiscal en una economía globalizada". Revista Galega de Economía, vol. 20, núm. 2, 1-37.

Dirección General de Comercio e Inversiones (2014) Boletín de Inversiones Exteriores Directas. Flujos 2012. Madrid: Ministerio de Economía y Competitividad. Fernández, Juan Carlos (2014): "El redlining de la señora Watanabe: El impacto de la depresión en la geografía financiera de la deuda soberana", en J. M. Albertos y J. L. Sánchez (eds.) Geografía de la crisis económica en España. Valencia: Universitat de Valencia, 77-100. 
Feroldi, Valentina y Gaffeo, Edoardo (2013) At the Core of the International Financial. Universidad de Trento. [Disponible en URL: $<$ http://ssrn.com/abstract=2250318 $>$. Consultado el 24 de Mayo de 2015].

Gai, Prasanna, y Kapadia, Sujit (2010) Contagion in financial networks. Bank of England. Working Paper 383.

Gómez Lende, Sebastián (2014) "Circulación del capital y división del trabajo: reorganización de la red financiera y reestructuración del sistema bancario en Argentina (1991-2008)". Ateliê Geográfico, vol. 8, núm. 2, 7-37.

Greene, Ronald Walter, y Kuswa, Kevin Douglas (2012) "From the Arab Spring to Athens, From Occupy Wall Street to Moscow. Regional Accents and the Rhetorical Cartography of Power". Rhetoric Society Quarterly, vol. 42, núm. 3, 271288.

Hale, Galina (2012) "Bank relationships, business cycles, and financial crises". Journal of International Economics, vol. 88, núm. 2, 312-325.

Hale, Galina (2014) The Euro and the Geography of International Debt Flows. Federal Reserve Bank of San Francisco. University of California, Berkeley, NBER and CEPR.

Harvey, David (2012) El enigma del capital y las crisis del capitalismo. Madrid: Akal.

Hobza, Alexander, y Zeugner, Stefan (2014) The "imbalanced balance" and its unravelling: current accounts and bilateral financial flows in the euro area. European Economy. Economic Papers 520.

Hondroyiannis, George; Kelejian, Harry, y Tavlas, George (2009) "Spatial Aspects of Contagion among Emerging Economies". Spatial Economic Analysis, vol. 4, núm. 2, 191-211.

ICE (2013) “Inversiones Exteriores Directas en 2012”. Boletín Económico del ICE, núm. 3041, 89-114.

Kelejian, Harry; Tavlas, George, y Hondroyiannis, George (2006) "A Spatial Modelling Approach to Contagion Among Emerging Economies". Open Economies Review, vol. 17, núm. 4-5, 423-441.

Kleimeier, Stefanie; Sander, Harald, y Heuchemer, Sylvia (2013) "Financial crises and cross-border banking: New evidence." Journal of International Money and Finance, vol. 32, 884-915.

Kleimeier, Stefanie; Sander, Harald, y Heuchemer, Sylvia (2014) The resurgence of cultural borders in international finance during the financial crisis: Evidence from Eurozone cross-border depositing. Research Memorandum 13, Maastricht University.

Milesi-Ferretti, Gian-Maria, y Tille, Cédric (2011) "The great retrenchment: international capital flows during the global financial crisis". Economic Policy, vol. 26, núm. 66, 289-346.

Nagurney, Anna y Ke (2001) "Financial networks with intermediation". Quantitative Finance, vol. 1, 441-451. 
Nagurney, Anna, y Cruz, José (2003) "International financial networks with intermediation: modeling, analysis, and computations". Computational Management Science, vol. 1, núm. 1, 31-58.

OCDE (2013) "Foro Global sobre la Transparencia y el Intercambio de Información con Fines Fiscales". 6th Meeting of the Global Forum on Transparency and Exchange of Information for Tax Purposes. Declaración de Resultados. Yakarta (Indonesia).

Olivié, Iliana; Pérez, Aitor, y Macías, Carlos (2010) La "caja negra” del impacto de la inversión directa en el desarrollo: propuesta de un marco teórico. Real Instituto Elcano, Documento de Trabajo 24/2010 [Puesto en línea el 20 de Julio de $2010 . \quad$ URL: $<$ http://www.realinstitutoelcano.org/wps/portal/rielcano/contenido?WCM_GLO BAL_CONTEXT=/elcano/elcano_es/zonas_es/dt24-2010>. Consultado el $13 \mathrm{de}$ Diciembre de 2014].

Olivié, Iliana; Pérez, Aitor, y Macías, Carlos (2011) Inversión Directa Extranjera y desarrollo: recomendaciones a la cooperación española. Real Instituto Elcano. Documento de Trabajo 7/2011 [Puesto en línea el 3 de Marzo de 2011. URL: $<$ http://www.realinstitutoelcano.org/wps/portal/rielcano/contenido?WCM_GLO BAL_CONTEXT=/elcano/elcano_es/zonas_es/cooperacion+y+desarrollo/dt72011>. Consultado el 13 de Diciembre de 2014].

Palmberg, Johanna (2012) "Spatial concentration in the financial industry", en D. E. Andersson (ed.) Spatial Market Process (Advances in Austrian Economics, vol. 16) Bingley (Reino Unido): Emerald Group, 313-333.

Prats, Jordi, y Marín, Carlos (2010) "Corrección de la doble imposición en inversiones circulares". Estrategia Financiera, núm. 277, 56-63.

Seo, Bongman (2011) "Geographies of Finance: Centers, Flows, and Relations". Hitotsubashi Journal of Economics, vol. 52, núm. 1, 69-86.

Stiglitz, Joseph (2010) Caída Libre: El libre mercado y el hundimiento de la economía mundial. Madrid: Editorial Taurus.

UNCTAD (2014) Informe sobre las inversiones en el mundo 2013. Las cadenas de valor mundiales: inversión y comercio para el desarrollo. Nueva York y Ginebra: Naciones Unidas.

Vázquez Rozas, Emilia (2009) "Foreign direct investment in the southern and the new acceding european countries: replacement of activities?". Regional and Sectoral Economic Studies, vol. 9, núm. 1, 117-128.

Villaverde, José y Maza, Adolfo (2012) "Foreign direct investment in Spain: Regional distribution and determinants". International Business Review, vol. 21, núm. 4, 722-733.

Warde, Ibrahim (2012) “¿De dónde vienen los productos derivados?”. El Atlas Financiero. Valencia: Ediciones Cybermonde, 50-52.

Weatherall, James Owen (2013) Cuando los físicos asaltaron los mercados. Barcelona: Editorial Ariel. 